\title{
In silico characterization and structural modeling of bacterial metalloprotease of family M4
}

\author{
Rajnee Hasan * (D), Md. Nazmul Haq Rony and Rasel Ahmed
}

\begin{abstract}
Background: The M4 family of metalloproteases is comprised of a large number of zinc-containing metalloproteases. A large number of these enzymes are important virulence factors of pathogenic bacteria and therefore potential drug targets. Whereas some enzymes have potential for biotechnological applications, the M4 family of metalloproteases is known almost exclusively from bacteria. The aim of the study was to identify the structure and properties of M4 metalloprotease proteins.
\end{abstract}

Results: A total of 31 protein sequences of M4 metalloprotease retrieved from UniProt representing different species of bacteria have been characterized for various physiochemical properties. They were thermostable, hydrophillic protein of a molecular mass ranging from 38 to $66 \mathrm{KDa}$. Correlation on the basis of both enzymes and respective genes has also been studied by phylogenetic tree. B. cereus M4 metalloprotease (PDB ID: 1NPC) was selected as a representative species for secondary and tertiary structures among the M4 metalloprotease proteins. The secondary structure displaying 11 helices $(\mathrm{H} 1-\mathrm{H} 11)$ is involved in 15 helix-helix interactions, while $4 \beta$-sheet motifs composed of $15 \beta$-strands in PDBsum. Possible disulfide bridges were absent in most of the cases. The tertiary structure of B. cereus M4 metalloprotease was validated by QMEAN4 and SAVES server (Ramachandran plot, verify 3D, and ERRAT) which proved the stability, reliability, and consistency of the tertiary structure of the protein. Functional analysis was done in terms of membrane protein topology, disease-causing region prediction, proteolytic cleavage sites prediction, and network generation. Transmembrane helix prediction showed absence of transmembrane helix in protein. Protein-protein interaction networks demonstrated that bacillolysin of $B$. cereus interacted with ten other proteins in a high confidence score. Five disorder regions were identified. Active sites analysis showed the zinc-binding residues-His-143, His-147, and Glu-167, with Glu-144 acting as the catalytic residues.

Conclusion: Moreover, this theoretical overview will help researchers to get a details idea about the protein structure and it may also help to design enzymes with desirable characteristics for exploiting them at industrial level or potential drug targets.

Keywords: M4 family metalloprotease, Bacteria, Structural and functional analysis, Phylogenetic tree, Potential drug targets

\footnotetext{
* Correspondence: rajnee@jutegenome.org

Basic and Applied Research on Jute Project, Bangladesh Jute Research

Institute, Manik Mia Avenue, Dhaka 1207, Bangladesh
}

\section{Springer Open}

(c) The Author(s). 2021 Open Access This article is licensed under a Creative Commons Attribution 4.0 International License, which permits use, sharing, adaptation, distribution and reproduction in any medium or format, as long as you give appropriate credit to the original author(s) and the source, provide a link to the Creative Commons licence, and indicate if changes were made. The images or other third party material in this article are included in the article's Creative Commons licence, unless indicated otherwise in a credit line to the material. If material is not included in the article's Creative Commons licence and your intended use is not permitted by statutory regulation or exceeds the permitted use, you will need to obtain permission directly from the copyright holder. To view a copy of this licence, visit http://creativecommons.org/licenses/by/4.0/. 


\section{Background}

Proteases are enzymes that can hydrolyze proteins and are composed of a diverse group of exoproteases and endoproteases depending on their activity. Based on their catalytic mechanism, endoproteases are divided into aspartic proteases, cysteine proteases, metalloproteases, serine proteases, and threonine proteases [1]. Proteases that contain one or two divalent metal ions in their active sites are known as metalloproteases. While most of the metalloproteases contain $\mathrm{Zn}^{2+}$, in some cases, $\mathrm{Ca}^{2+} \mathrm{Mg}^{2+}, \mathrm{Ni}^{2+}$, or $\mathrm{Cu}^{2+}$ are also found [2]. The role of the catalytic metal ions in metalloproteases is to activate the water molecule, which serves as a nucleophile in catalysis. Metalloproteases are produced by all species of plants, animals, and microorganisms. They are involved in many biological processes such as embryonic development, morphogenesis, processing of peptide hormones, release of cytokines and growth factors, cell-cell fusion, cell adhesion and migration, intestinal absorption of nutrients, viral polyprotein processing, bacterial cell wall biosynthesis, and metabolism of antibiotics [3]. Due to their active relation with many diseases, extracellular metalloproteases have been widely studied [4].

All the well-characterized proteinases to date belong to one or more family in MEROPS database (http:// MEROPS.sanger.ac.uk/). The current MEROPS database (release 12.1) classifies metallopeptidases into 76 families, which are grouped into sixteen clans based on metal ion binding motifs and similarities to their 3-D structure. The proteases in the M4 family belong to clan MA, a big family of metalloproteases that degrade extracellular proteins and peptides for bacterial nutrition. Metalloproteases of the family M4 comprise different types of peptidases, thermolysin, vibriolysin, pseudolysin, coccolysin, aureolysin, vimelysin, lambda toxin, bacillolysin, stearolysin, gelatinase, elastase, etc.

Some of the metalloproteases are widely used in the food, medicine, brewing, leather, film, and baking industries. Thermolysin from Bacillus thermoproteolyticus has diverse industrial usage. Thermolysin is used as a peptide and ester synthetase in the production of $\mathrm{N}$ carbobenzoxy-L-aspartyl-L-phenylalaninemethyl ester (ZAsp-Phe-OMe), the precursor to the artificial sweetener aspartame [5-7]. Thermolysin is also used in biotechnology industry as a non-specific proteinase to obtain fragments for peptide sequencing. Thermozymes, enzymes from thermophilic microorganisms, have unique characteristics such as extreme temperature persistence, high stability in organic solvents, strict substrate specificity, and $\mathrm{pH}$ stability. For these features, thermozymes have been considerably used in many industrial applications [8-11]. Vimelysin from Vibrio str.T1800 has pertinence in peptide condensation reactions because of its high activity in organic solvents [12]. In addition, vibriolysin from Vibrio proteolyticus are utilized in several industrial as well as biomedical applications [10, 11]. It mediates the coupling of $\mathrm{N}$-protected aspartic acid and phenylalanine methyl ester to yield $\mathrm{N}$-protected aspartylphenylalaninemethylester, a precursor of the sweetener aspartame, whereas a new metalloprotease of the M4 family, VP9, was identified in Vibrio pomeroyi strain 12613 from Atlantic seawater that was able to hydrolyze casein and gelatin [13]. Neutrase from B. subtilis was began to use in industrial sector in 1995 for the synthesis of Celite-545 and followed by 1997 for the synthesis of Polyamide-PA6 [14, 15]. Another metalloprotease of M4 family, pseudolysin from $P$. aeruginosa, can be developed for peptide synthesis, which has been demonstrated to be a suitable catalyst for peptide bond formation through reverse proteolysis [16]. M4 metalloprotease obtainable from Actinobacteria is used for wort production [17]. Thus, proteinases of the M4 family have a huge potential for industrial context and have also been found to be a useful catalyst in protein engineering $[18,19]$.

Members of the M4 family that are considered virulence factors of pathogens can also be used as targets in drug and vaccine development [20,21]. Lambda toxin of Clostridium perfringens activates the precursors of clostridial potent toxins and degrades various host proteins that contribute to innate or adaptive immune defense against infections [22]. Hemagglutinin from Vibrio cholerae are the causative agents for gastritis, peptic ulcer, gastric carcinoma [23] and cholera. It has also been shown to affect intracellular tight junctions by degrading occluding [24]. In addition, vibriolysin from $V$. proteolyticus is used for the removal of necrotic tissue from wounds such as burns or cutaneous ulcers and is reported to stimulate the healing of partial-thickness burn wounds [25]. The peptidase from Legionella may have role in the virulence of Legionnaire's disease and pneumonia [26] as it cleaves $\alpha_{1}$-antitrypsin [27], tumor necrosis factor $\alpha$, interleukin 2, and CD4 on human $\mathrm{T}$ cell surfaces [28]. Pseudolysin, an extracellullar elastase of Pseudomonas aeruginosa, is involved in chronic ulcers by degradation of human wound fluids and human skin proteins [29]. Again, Pseudomonas aeruginosa produces elastase B in the hemolymph after infection of larval silkworm contributes to the growth of $P$. aeruginosa in the silkworm and pathogenicity of $P$. aeruginosa to the host [30]. Based on the current knowledge, it is reasonable to believe that particular metalloproteinases associated with human pathogens have been recognized as prominent virulence factors and their therapeutic inhibition has become a novel strategy in the development of secondgeneration antibiotics [31, 32].

For a successful integration of M4 metalloprotease in large-scale industrial processes and therapeutic use, a detailed understanding of the enzyme is prerequisite. 
The present study was aimed to be utilize in silico tools for the characterization of M4 metalloprotease from different bacterial species for their physicochemical characteristics; primary, secondary, and tertiary structure of proteins; functional analysis; domains and motifs; protein model; and phylogenetic analysis.

\section{Methods}

\section{Sequence retrieval and alignment}

A total of 31 different M4 metalloprotease sequences of bacterial origin have been retrieved from UniProt (https://www.uniprot.org/). Corresponding gene sequences of 31 bacterial M4 metalloprotease proteins were retrieved from NCBI (https://www.ncbi.nlm.nih. gov/). The UniProtKB of protein sequences, accession numbers of the gene sequences along with the source organisms were listed in Supplementary Table 1. Clustal Omega (https://www.ebi.ac.uk/Tools/msa/clustalo/) [33] algorithm was used for the alignment of retrieved protein sequences through multiple sequence alignments and the alignments were inspected using CLC sequence viewer 8.0 (http://www.clcbio.com).

\section{Determination of physical parameters of the proteins}

The different physicochemical properties of M4 metalloprotease enzymes were computed using ExPASy'sProtParam tool (http://web.expasy.org/protparam) [34] and these properties were deduced from a protein sequence. The ProtParam includes the following computed parameters: molecular weight, isoelectric point (pI), extinction coefficient (EC-quantitative study of protein-protein and protein-ligand interactions), instability index (IIstability of proteins), aliphatic index (AI-relative volume of protein occupied by aliphatic side chains), and Grand Average of Hydropathicities (GRAVY - sum of all hydropathicity values of all amino acids divided by number of residues in a sequence).

\section{Phylogenetic tree construction}

Two different phylogenetic trees were constructed from amino acid sequences and from gene sequences using the MEGAX software [35] to compare evolutionary relatedness of the taxa. The evolutionary history was inferred using the neighbor-joining method [36]. For amino acid sequence, the evolutionary distances were computed using the Poisson correction method [37] whereas for gene sequence the evolutionary distances were computed using the maximum composite likelihood method [38].

\section{Primary structure analysis}

For primary structure analysis, viz., the amino acids present in polypeptide chain, ExPASy-ProtParam tool had been used. For domain search, the Pfam site (http://
www.sanger.ac.uk/Software/Pfam/search.shtml) was used. Motif analysis was done using MEME (http:// meme.sdsc.edu/meme/meme.html) [39]. The conserved protein motifs deduced by MEME were subjected to biological functional analysis using protein BLAST and domains were studied with Interproscan (http://www.ebi. ac.uk/interpro/search/sequence/) providing the best possible match based on highest similarity score.

\section{Secondary structure analysis}

Secondary structure analysis of retrieved bacterial M4 metalloproteases included number of $\alpha$-helices, $\beta$-turn, extended strand, $\beta$-sheet, and coils which were performed by SOPMA from the Network Protein Sequence Analysis (NPS@) server (https://npsa-prabi.ibcp.fr/cgibin/npsa_automat.pl?page=npsa_sopma.html) [34]. The secondary motif map and topology diagram were calculated using the PDBsum tool (http://www.ebi.ac.uk/ thornton-srv/databases/cgibin/pdbsum/GetPage.

pl?pdbcode=index.html) [40]. The consensus secondary structure contents and predicted disulfide patterns of each protein were tabulated. The presence of disulfide bridges was analyzed using the CYS-REC tool (http:// linux1.softberry.com/berry.phtml) which predicted the most probable bonding patterns between available cysteine residues.

\section{Tertiary structure analysis and validation}

Among the 31 strains, B. cereus was selected as a representative of all the strains to predict the tertiary structure of M4 metalloprotease protein. SWISS-MODEL 3.1.0 (https://swissmodel.expasy.org/) was used to build the 3D models of $B$. cereus M4 metalloprotease sequence (PDB ID: 1NPC) with energy minimization parameters [41]. PyMOL (Schrödinger Inc.) was used to visualize publishable image of the model [42]. Structure evaluation was the most important component of structure prediction. Predicted protein model of M4 metalloprotease of B. cereus was evaluated and verified from both QMEAN (https://swissmodel.expasy.org/qmean/) and SAVES (https://servicesn.mbi.ucla.edu/SAVES/) server. Ramachandran plot generated from RAMPAGE server (http://mordred.bioc.cam.ac.uk/ rapper/rampage.php) [43]. Verify3D [44] and ERRAT [45] were evaluated from SAVES. The overall quality of the structure was obtained through Ramachandran plot. Verify3D analyzed the compatibility of an atomic model (3D) with its own amino acid sequence (1D) [46]. The verification of the crystallographic structure of proteins was done by Errate.

\section{Functional analysis}

Function prediction was done in terms of membrane protein topology, disease-causing region prediction, 
proteolytic cleavage sites prediction and network generation. TMHMM 2.0 tool (www.cbs.dtu.dk/services/ TMHMM) was used to understand membrane protein topology, more specifically if the protein was membrane spanning or extracellular in nature [47]. GlobPlot 2.3 (http://globplot.embl.de/) was used to identify regions of globularity and disorder within protein sequences. This web service looks for order/globularity or disorder tendency in the query protein based on a running sum of the propensity for an amino acid by searching domain databases and sets of disordered proteins [48]. Proteolytic cleavage sites were identified by using a web-based tool peptide cutter (http://web. expasy.org/peptide_cutter/) [34], which predicted the proteolytic cleavage sites and sites cleaved by chemicals in a given protein sequence. Identification of protein-protein interaction was carried out by STRI NG 11.0 (https://string-db.org/) [49]. STRING is a biological database which is used to construct protein-protein interaction network for different known and predicted protein interactions.

\section{Active site prediction}

The Computed Atlas of Surface Topography of proteins 3.0 (CASTp 3.0) server (http://sts.bioe.uic.edu/) [50] was used to predict active binding site pockets of protein. It includes annotated functional information of specific residues on the protein structure.

\section{Results}

\section{Sequence retrieval and alignment}

The protein sequences of M4 metalloprotease enzymes belonging to different bacterial strains were retrieved from UniProt and FASTA format of these sequences have been selected based on the overall quality parameters in UniProt tool (Supplementary table 1). The homology search and multiple sequence alignment of these 31 M4 metalloprotease sequences revealed a little stretch of conserved region ranging from the amino acid residues 117-146, 304-323, 451-533, 542-579, 595-624, 652-667, and $705-720$ as shown in Figure S1. Few highly conserved amino acids were also observed for most of the sequences. Twenty-two $100 \%$ conserved positions were found in aligned region comprising nonpolar amino acid, Ala, Leu, Gly, and Pro, Val; polar amino acid, Asn and Ser; aromatic amino acid, Tyr; acidic amino acid, Glu and Asp; and basic amino acid, Arg and His. Alignment of 31 M4 metalloproteases revealed a conserved region (HELTE) occurring between amino acid positions " $542-546$ " in the region blocked with pink areas of Fig. 1.

\section{Phylogenetic tree construction}

To compare evolutionary relationship, two phylogenetic trees were constructed with MEGAX, one consisted of amino acid sequences of 31 bacterial M4 metalloprotease enzymes (Fig. 2a), and another one is their corresponding gene sequences (Fig. 2b). The horizontal

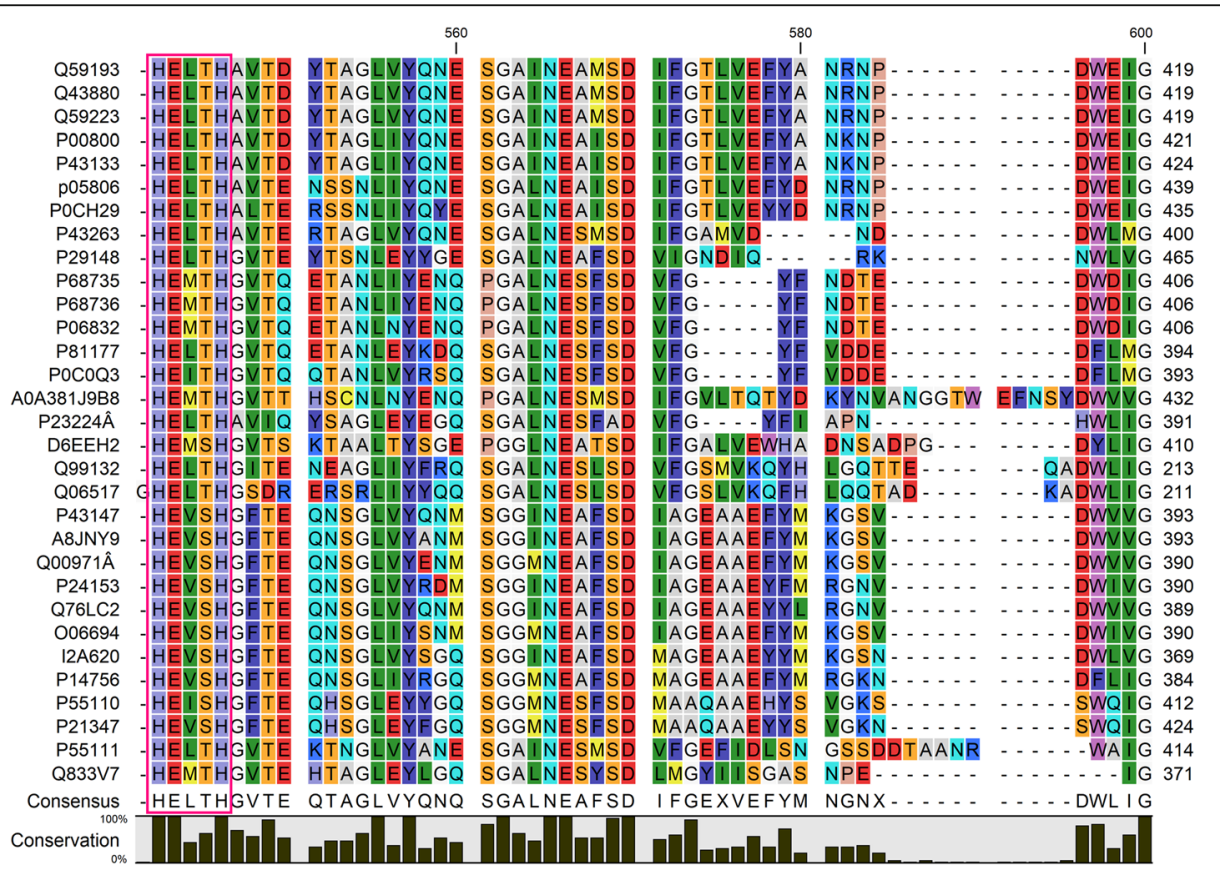

Fig. 1 Multiple sequence alignment of M4 metalloprotease amino acid sequences showing the zinc-binding motif "HEXXH" in a pink box 


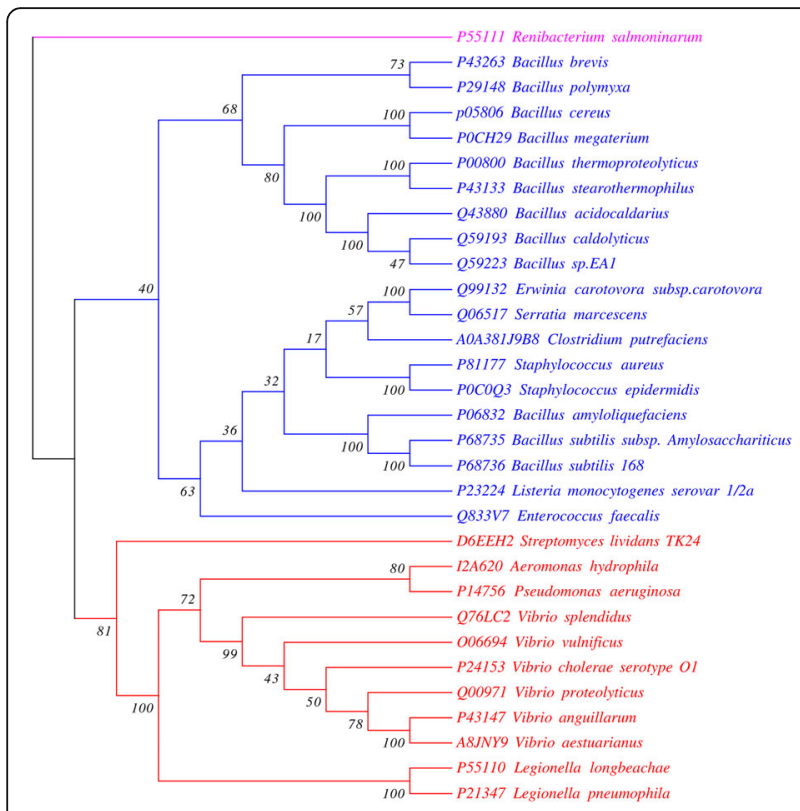

(A)

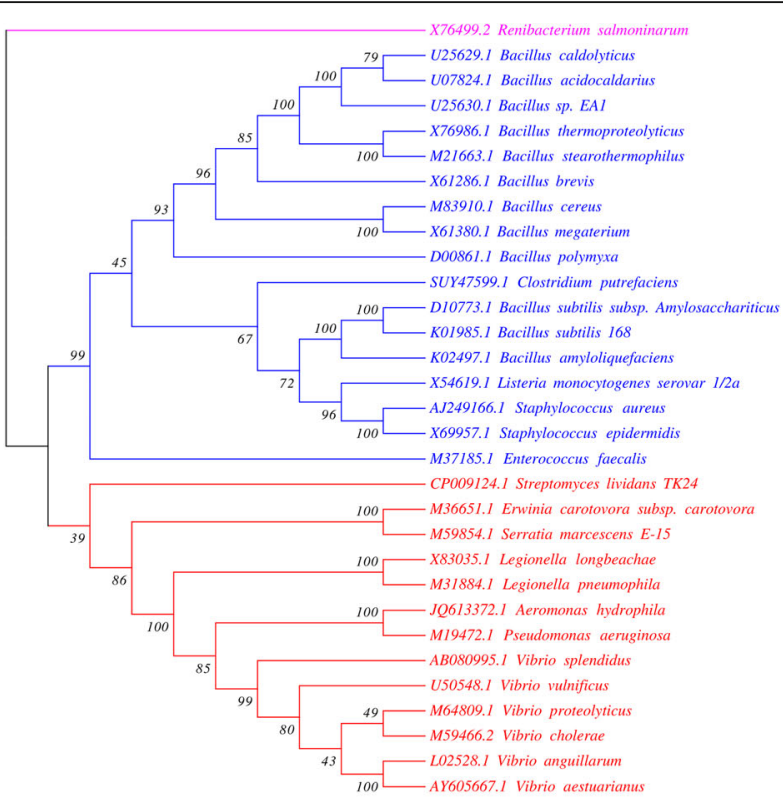

(B)

Fig. 2 Phylogenetic tree of 31 different M4 metalloproteases of bacterial origin by Neighbor-joining method using MEGA X. a Phylogenetic tree constructed with 31 amino acid sequences of bacterial M4 metalloprotease. $\mathbf{b}$ Phylogenetic tree constructed with 31 gene sequences of bacterial M4 metalloproteases

branches represented evolutionary lineages changing over time. The longer the branch, the larger the amount of change. In Fig. 2a the optimal tree with the sum of branch length $=8.83019656$ was shown. Here, amino acid sequences were distributed into two main clades and an outgroup. Dominant clade consisted of amino acid sequences from mostly gram-positive bacteria (except Streptomyces lividans TK24; D6EEH2) along with two gram-negative bacteria, Erwinia_carotovora_subsp. carotovora; Q99132 and Serratia marcescens; Q06517 and were marked as blue (Fig. 2a). From this figure, it was observed that the two strains Erwinia_carotovora subsp._carotovora; Q99132 and Serratia marcescens; Q06517 clustered with Clostridium putrefaciens; A0A381J9B8 which revealed sequence level similarity of these protein sequences. Whereas amino acid sequences from rest gram-negative bacteria with Streptomyces lividans TK24, D6EEH2 exhibited high similarity index and they belonged to another clade and were represented as red (Figure 2a).

In Fig. $2 \mathrm{~b}$ another phylogenetic tree was constructed to find out the relation among gene sequences of corresponding protein. The optimal tree with the sum of branch length $=20.01342277$ was shown. Here, gene sequences of gram-positive bacteria (marked as blue) and gram-negative bacteria (marked as red) formed separate clusters signifying the sequence-based similarity. In both cases, the outgroup contained Renibacterium salmoninarum marked as pink.

\section{Determination of physical parameters of the proteins}

In confirmation of the uniqueness of any protein or enzyme molecule, characterization of the biochemical features of these molecules play the preliminary role [34]. The physicochemical features of protease sequences obtaining from ExPASy ProtParam were summarized in Table 1. The total number of amino acid residues ranged from 347 to 611 with variable molecular weights. The pI values of all the proteins showed broad range of 4.8810 . The variability was also observed among these proteins in terms of other physiochemical parameters like negative charge residues (Asp and Glu), positively charged amino acid residues (His, Arg, Lys), hydropathicity (GRAVY), and extinction coefficient (EC) which were listed in Table 1.

\section{Primary sequence analysis}

The primary structure analysis of M4 metalloprotease enzymes included amino acid distribution, motif, and domain analysis. The amino acid distribution was represented as a heatmap in Fig. 3 which showed that the most abundant amino acid was Ala and the least common amino acid was cysteine.

A total of 10 motifs were observed in 31 sequences when subjected to MEME and depicted in Fig. 4. The motifs with width and best possible match amino acid sequences were given in Table 2. A set of 41 amino acid residues, i.e., PSGSJDVVAHELTHGVTEQTAGLVYZNZSGAJNEAFSD IFG representing motif 1 was uniformly observed in all 
Table 1 Biochemical features of M4 metalloprotease protein sequences from different bacterial species

\begin{tabular}{|c|c|c|c|c|c|c|c|c|c|c|c|}
\hline S.N. & Bacteria Name & UniProtKB & Seq length & MW & $\mathrm{pl}$ & $\mathrm{EC}$ & li & $\mathbf{A i}$ & GRAVY & $-\mathbf{R}$ & $+\mathrm{R}$ \\
\hline 1 & Aeromonas hydrophila & I2A620 & 590 & 62969.1 & 6.02 & 99615 & 25.25 & 69.47 & -0.245 & 52 & 46 \\
\hline 2 & Bacillus thermoproteolyticus & P00800 & 548 & 60103.9 & 5.53 & 81140 & 26.43 & 76.35 & -0.392 & 59 & 48 \\
\hline 3 & B. stearothermophilus & P43133 & 551 & 60616.6 & 5.82 & 81140 & 26.78 & 76.46 & -0.397 & 59 & 51 \\
\hline 4 & B. subtilis Amylosacchariticus & P68735 & 521 & 56521.7 & 7.16 & 63720 & 30.09 & 74.38 & -0.51 & 53 & 53 \\
\hline 5 & B. subtilis & P68736 & 521 & 56521.7 & 7.16 & 63720 & 30.09 & 74.38 & -0.51 & 53 & 53 \\
\hline 6 & B. cereus & P05806 & 566 & 60919.3 & 5.7 & 75640 & 29.23 & 69.98 & -0.484 & 64 & 56 \\
\hline 7 & B. brevis & P43263 & 527 & 58645.7 & 5.33 & 90650 & 29.44 & 68.67 & -0.598 & 70 & 50 \\
\hline 8 & B. polymyxa & P29148 & 590 & 63528.7 & 4.88 & 86640 & 26.19 & 75.1 & -0.43 & 74 & 50 \\
\hline 9 & B. caldolyticus & Q59193 & 546 & 59770.6 & 5.39 & 102110 & 29.36 & 73.97 & -0.372 & 60 & 48 \\
\hline 10 & B. megaterium & $\mathrm{POCH} 29$ & 562 & 60948.6 & 8.4 & 83090 & 29.61 & 70.64 & -0.52 & 55 & 58 \\
\hline 11 & B. amyloliquefaciens & P06832 & 521 & 56840.3 & 8.2 & 65210 & 26.14 & 75.09 & -0.538 & 53 & 55 \\
\hline 12 & B. acidocaldarius & Q43880 & 546 & 59769.6 & 5.47 & 102110 & 29.95 & 73.97 & -0.372 & 59 & 48 \\
\hline 13 & Bacillus sp. EAl & Q59223 & 546 & 59812.7 & 5.39 & 102110 & 29.08 & 74.51 & -0.363 & 60 & 48 \\
\hline 14 & Clostridium putrefaciens & A0A381J9B8 & 553 & 61718.7 & 4.9 & 77255 & 31.24 & 77.72 & -0.444 & 73 & 49 \\
\hline 15 & Enterococcus faecalis & Q833V7 & 510 & 55503.8 & 4.97 & 48250 & 22.68 & 81.98 & -0.348 & 67 & 43 \\
\hline 16 & Erwinia carotovora & Q99132 & 347 & 38828.4 & 5.48 & 51005 & 38.81 & 79.31 & -0.422 & 42 & 25 \\
\hline 17 & Legionella longbeachae & P55110 & 529 & 58712.6 & 5.71 & 93880 & 36.35 & 65.46 & -0.435 & 59 & 46 \\
\hline 18 & Legionella pneumophila & P21347 & 543 & 60704.1 & 5.27 & 95370 & 34.62 & 64.83 & -0.491 & 66 & 47 \\
\hline 19 & Listeria monocytogenes & P23224 & 510 & 57411 & 6.61 & 62020 & 27.85 & 80.53 & -0.477 & 68 & 65 \\
\hline 20 & Pseudomonas aeruginosa & P14756 & 498 & 53687.1 & 6.28 & 65000 & 26.9 & 73.49 & -0.271 & 50 & 46 \\
\hline 21 & Renibacterium salmoninarum & P55111 & 548 & 56378.6 & 5.2 & 47245 & 17.53 & 79.73 & -0.095 & 47 & 40 \\
\hline 22 & Staphylococcus aureus & P81177 & 509 & 56320.9 & 5.02 & 56730 & 23.75 & 68.21 & -0.732 & 80 & 56 \\
\hline 23 & Staphylococcus epidermidis & P0COQ3 & 507 & 55813.5 & 5.35 & 55240 & 29.37 & 69.45 & -0.691 & 68 & 56 \\
\hline 24 & Streptomyces lividans & D6EEH2 & 547 & 56812.3 & 4.75 & 84145 & 19.32 & 75.43 & -0.235 & 71 & 43 \\
\hline 25 & Serratia marcescens & Q06517 & 352 & 38515.3 & 10 & 49640 & 52.68 & 65.26 & -0.698 & 29 & 48 \\
\hline 26 & Vibrio proteolyticus & Q00971 & 609 & 66362.5 & 5.07 & 88045 & 30.55 & 64.84 & -0.359 & 64 & 45 \\
\hline 27 & Vibrio anguillarum & P43147 & 611 & 66726.5 & 5.7 & 92055 & 30.83 & 68.43 & -0.292 & 53 & 44 \\
\hline 28 & Vibrio aestuarianus & A8JNY9 & 611 & 66344.9 & 5.33 & 93545 & 30.57 & 72.9 & -0.252 & 54 & 41 \\
\hline 29 & Vibrio vulnificus & O06694 & 606 & 65613.9 & 6.17 & 93085 & 32.45 & 66.67 & -0.341 & 54 & 48 \\
\hline 30 & Vibrio cholerae & P24153 & 609 & 65891.2 & 5.26 & 92055 & 25.18 & 68.82 & -0.25 & 53 & 39 \\
\hline 31 & Vibrio splendidus & Q76LC2 & 607 & 65879 & 5.74 & 88045 & 30.39 & 68.29 & -0.332 & 56 & 46 \\
\hline
\end{tabular}

sequences revealing its identity with the peptidase_M4 and Peptidase_M4_C domains (Table 2). The order of amino acid residues "HELTH" in this sequence was associated with the active site of the enzyme. Motif 8 was uniformly observed in most of the proteases sequences except Q99132 (Erwinia carotovora) and Q06517 (Serratia marcescens) represented a signal peptide FTP domain which prevented premature activation of proteases [51]. The region of motif 7 was likely to have a protease inhibitory function since it belonged to the pepSY domain [52]. In case of motifs 3, 5 and 9 belonging to Peptidase_M4 domain were associated with the catalysis of the enzyme. The motifs 2, 4, and 6, belonging to Peptidase_M4_C domain, were important in order to the presence of alpha helix related with the flexibility of protein conformation and protein function. Motif 10 was observed only in five species from genus vibrio (Q00971, V. proteolyticus; P43147, V. anguillarum; A8JNY9, V. aestuarianus; O06694, V. vulnificus; and P24153, V. cholerae) along with I2A62, Aeromonas hydrophila.

\section{Secondary structure analysis}

The predicted secondary structure composition of M4 metalloprotease was determined using the NPS@ server which generated a consensus report from twelve secondary structure prediction methods. The secondary structure prediction server revealed that the enzyme is dominated by $41.64 \%$ of amino acid in random coils 


\section{Color Key}

Amino Acid Distribution

010

Value

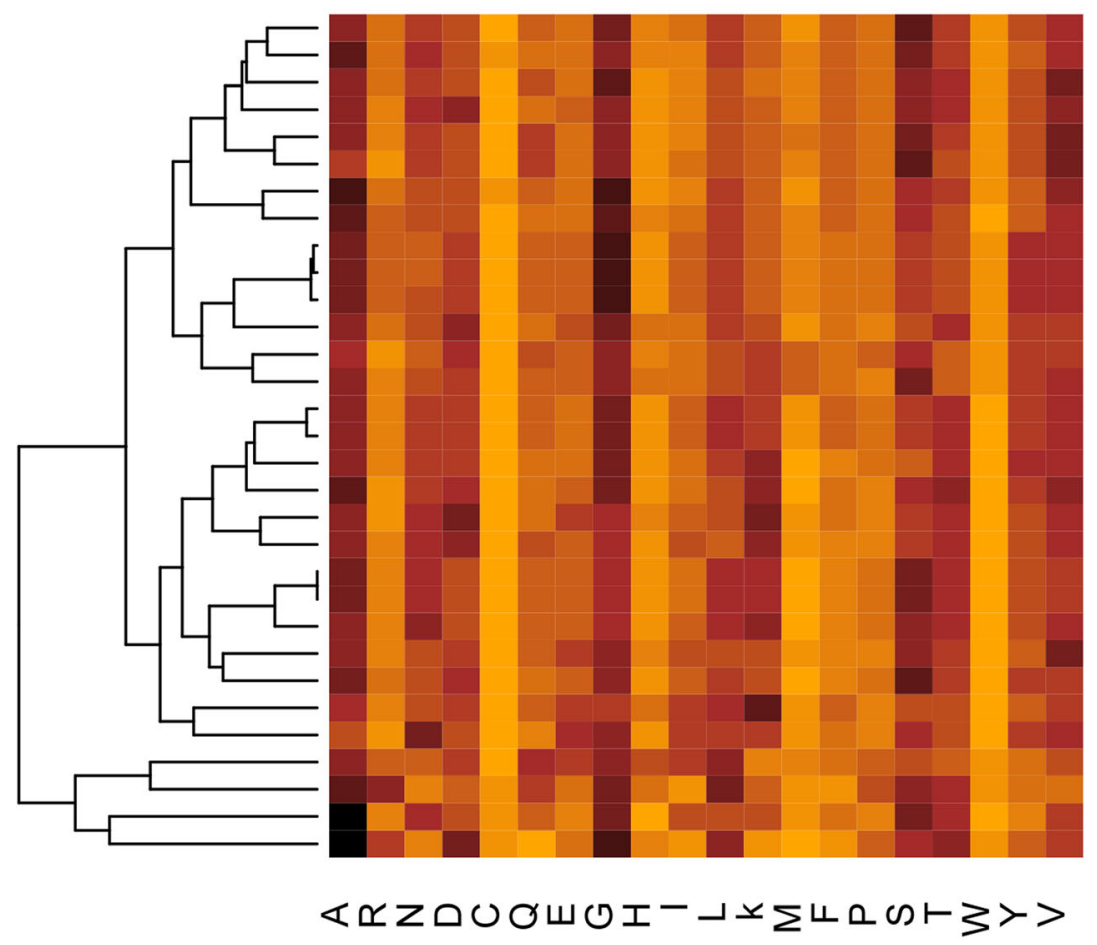

Q76LC2

006694
P24153

Q00971

P43147

A8JNY9
I2A620

P14756

Q59223

Q59193

P21347

P55110

P00800

P43133

P0CH29
P05806

P81177

POCOQ3

P68736

P68735

P06832

Q833V7

P23224

A०A3819988

Q99132

Q06517

P55111

D6EEH2

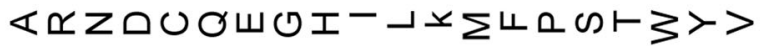

Fig. 3 Amino acids distribution in 31 different bacterial M4 metalloprotease enzymes

along with $32.12 \%$ of amino acids resided in $\alpha$-helices, while $20.36 \%$ of residues were in extended sheet. Finally, less amount of the amino acids was found in extended sheet region of $5.88 \%$ (Table 3).

A more detailed analysis of the secondary structural elements was performed using the PDBsum tool. Here, the amino acid sequence of M4 metalloprotease from $\mathrm{B}$. $\mathrm{Ce}$ reus was taken as template which is also known as Bacillolysin. The predicted secondary structures generated by the PDBsum tool in Fig. 5a were generally in an idea of the "structural coverage", how much the protein sequence of B. cereus M4 metalloprotease was actually represented by the 3D structure [53]. The secondary structure displaying 11 helices $(\mathrm{H} 1-\mathrm{H} 11)$ involved in 15 helix-helix interactions, while $4 \beta$-sheet motifs composed of $15 \beta$-strands. According to the diagram, the catalytic site lid ${ }^{143}$ HELT $\mathrm{H}^{147}$ was located within helix $\mathrm{H} 4$. This was also observed in the 3D structure. The topology of B. cereus M4 metalloprotease was illustrated in Fig. 5b which showed the arrangement and connectivity of the helices and strands in protein. Where the protein chain consisted of two domains, a $\mathrm{C}$-terminal domain and an $\mathrm{N}$-terminal domain were both folded into a mixed $\alpha / \beta$ topology.

Disulfide bonds play an important role in folding and stabilizing the unfolded form of the protein by lowering the entropy. Possible disulfide linkages in the primary structure were determined using CYS_REC was represented in Table 3. In most of the cases disulfide bridges were absent, as the prevalence of cysteine residues were very poor (Fig. 3).

\section{Tertiary structure analysis}

The tertiary structure of M4 metalloprotease was generated with the SWISS-MODEL using B. cereus M4 metalloprotease (PDB ID: 1NPC) as a template and PyMOL was used to visualize the model (Fig. 6). The active side lid was shown as a pink loop, four $\mathrm{Ca}^{2+}$ binding site was illustrated as pink and a $\mathrm{Zn}^{2+}$ binding site was as blue. This model was further verified by QMEAN4 and SAVE $\mathrm{S}$ server. QMEAN PDB result was represented in Fig. 7 


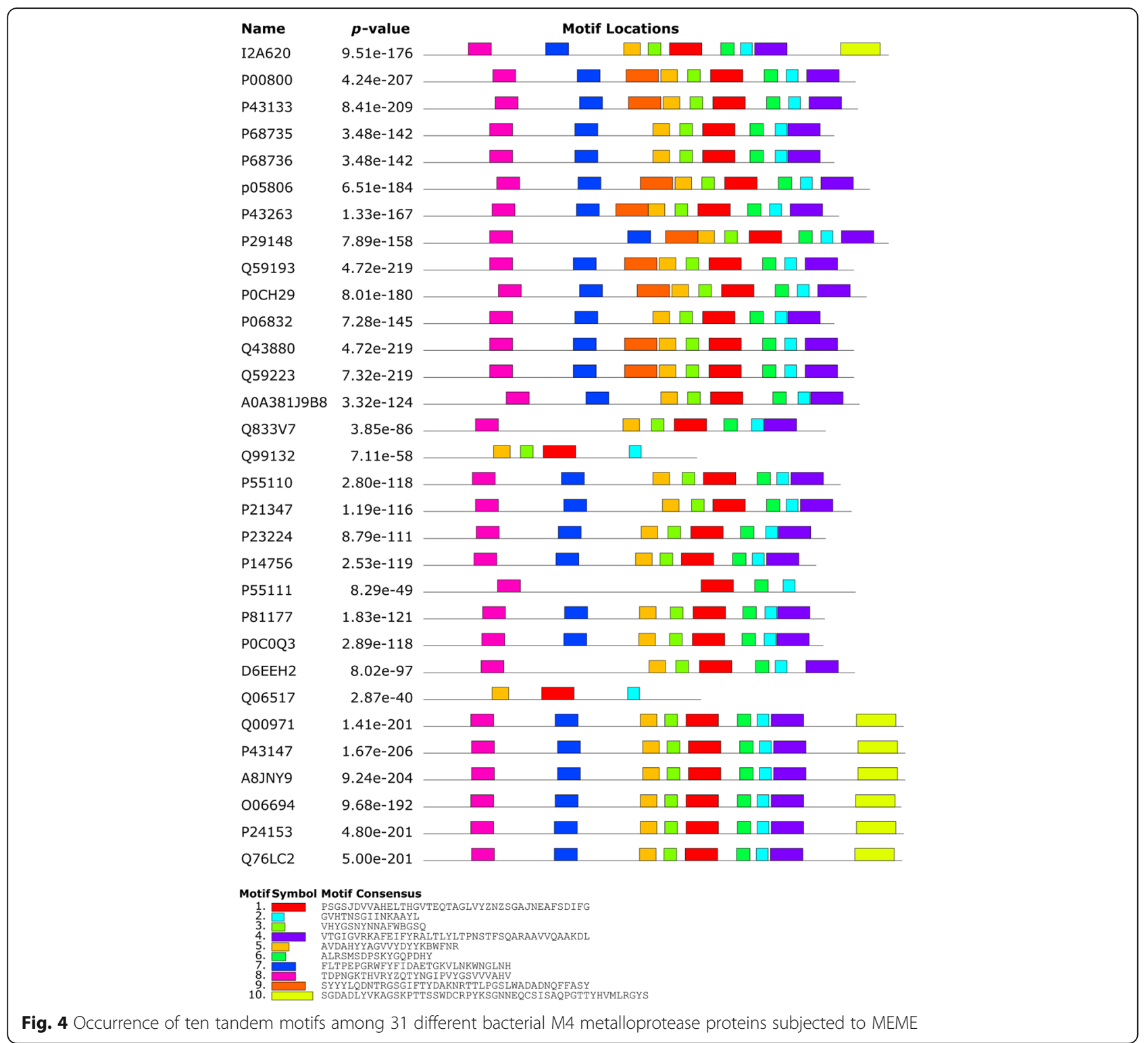

Table 2 Distribution of different motifs with best possible match amino acid sequences along with functional domains

\begin{tabular}{llll}
\hline Motif no. & Width & Best possible amino acids & Domain \\
\hline 1 & 41 & PSGSJDWAHELTHGVTEQTAGLVYZNZSGAJNEAFSDIFG & Peptidase_M4 and Peptidase_M4_C \\
2 & 15 & GVHTNSGIINKAAYL & Peptidase_M4_C \\
3 & 16 & VHYGSNYNNAFWBGSQ & Peptidase_M4 \\
4 & 41 & VTGIGVRKAFEIFYRALTLYLTPNSTFSQARAAWQAAKDL & Peptidase_M4_C \\
5 & 21 & AVDAHYYAGWYDYYKBWFNR & Peptidase_M4 \\
6 & 17 & ALRSMSDPSKYGQPDHY & Peptidase_M4_C \\
7 & 29 & FLTPEPGRWFYFIDAETGKVLNKWNGLNH & PepSY \\
8 & 29 & TDPNGKTHVRYZQTYNGIPVYGSWVAHV & FTP \\
9 & 41 & SYYYLQDNTRGSGIFTYDAKNRTTLPGSLWADADNQFFASY & Peptidase_M4 \\
10 & 50 & SGDADLYVKAGSKPTTSSWDCRPYKSGNNEQCSISAQPGTTYHVMLRGYS & PPC \\
\hline
\end{tabular}


Table 3 Predicted consensus secondary structure content and predicted disulfide patterns of M4 metalloproteases

\begin{tabular}{|c|c|c|c|c|c|c|c|}
\hline S.N. & Bacteria name & UniProtKB & Alpha helix & Extended strand & Beta turn & Random coil & Disulfide bridges prediction \\
\hline 1 & Aeromonas hydrophila & 12A620 & 28.98 & 23.39 & 7.12 & 40.51 & $214-550,240-452,481-561$ \\
\hline 2 & Bacillus thermoproteolyticus & P00800 & 35.58 & 20.99 & 4.74 & 38.69 & None \\
\hline 3 & B. stearothermophilus & P43133 & 32.67 & 20.33 & 5.26 & 41.74 & None \\
\hline 4 & B. subtilis subsp. Amylosacchariticus & P68735 & 27.64 & 20.54 & 6.14 & 45.68 & None \\
\hline 5 & B. subtilis & P68736 & 27.64 & 20.54 & 6.14 & 45.68 & None \\
\hline 6 & B. cereus & P05806 & 30.92 & 20.32 & 4.95 & 43.82 & None \\
\hline 7 & B. brevis & P43263 & 33.02 & 20.87 & 5.69 & 40.42 & None \\
\hline 8 & B. polymyxa & P29148 & 30.68 & 20.68 & 4.58 & 44.07 & None \\
\hline 9 & B. caldolyticus & Q59193 & 32.6 & 20.51 & 4.76 & 42.12 & None \\
\hline 10 & B. megaterium & $\mathrm{POCH} 29$ & 31.14 & 19.75 & 5.16 & 43.95 & None \\
\hline 11 & B. amyloliquefaciens & P06832 & 32.44 & 19 & 4.8 & 43.76 & None \\
\hline 12 & B. acidocaldarius & Q43880 & 31.14 & 21.25 & 5.13 & 42.49 & None \\
\hline 13 & Bacillus sp. (strain EA1) & Q59223 & 32.42 & 22.53 & 5.13 & 39.93 & None \\
\hline 14 & Clostridium putrefaciens & A0A381J9B8 & 33.45 & 19.89 & 5.79 & 40.87 & None \\
\hline 15 & Enterococcus faecalis & Q833V7 & 30.39 & 23.53 & 5.88 & 40.2 & None \\
\hline 16 & Erwinia_carotovora & Q99132 & 44.09 & 12.97 & 6.05 & 36.89 & None \\
\hline 17 & Legionella longbeachae & P55110 & 35.92 & 18.53 & 7.37 & 38.19 & 243-270, 349-498 \\
\hline 18 & Legionella pneumophila & P21347 & 32.04 & 19.15 & 7.55 & 41.25 & None \\
\hline 19 & Listeria monocytogenes & P23224 & 30.39 & 21.96 & 5.1 & 42.55 & None \\
\hline 20 & Pseudomonas aeruginosa & P14756 & 37.15 & 18.67 & 7.83 & 36.35 & $227-255,467-494$ \\
\hline 21 & Renibacterium salmoninarum & P55111 & 35.58 & 15.33 & 6.75 & 42.34 & 258-336, 519-535 \\
\hline 22 & Staphylococcus aureus & P81177 & 31.43 & 20.43 & 5.3 & 42.83 & None \\
\hline 23 & Staphylococcus epidermidis & P0COQ3 & 33.73 & 20.71 & 4.93 & 40.63 & None \\
\hline 24 & Streptomyces lividans TK24 & D6EEH2 & 27.24 & 21.57 & 5.48 & 45.7 & $336-438,338-481$ \\
\hline 25 & Serratia marcescens & Q06517 & 37.78 & 12.22 & 5.68 & 44.32 & 139-295 \\
\hline 26 & Vibrio proteolyticus & Q00971 & 30.21 & 22.66 & 6.73 & 40.39 & $231-570,257-581,473-502$ \\
\hline 27 & Vibrio anguillarum & P43147 & 30.61 & 21.93 & 5.73 & 41.73 & $260-572,476-583$ \\
\hline 28 & Vibrio aestuarianus & A8JNY9 & 29.3 & 22.59 & 7.53 & 40.59 & $234-260,476-572,505-583$ \\
\hline 29 & Vibrio vulnificus & 006694 & 30.03 & 21.45 & 6.27 & 42.24 & $231-257,473-502,569-580$ \\
\hline 30 & Vibrio cholerae $\mathrm{O} 1$ & P24153 & 28.74 & 23.97 & 7.06 & 40.23 & $231-473,257-581$ \\
\hline 31 & Vibrio splendidus & Q76LC2 & 30.81 & 23.06 & 5.6 & 40.53 & $230-568,256-579$ \\
\hline
\end{tabular}

and depicted the proper folding of protein into a compact three-dimensional field. Ramachandran plot measured the accuracy of protein model and the results were narrated in Fig. 8a. The profile score above zero in the Verify3D graph correspond to the acceptable environment of the model, in Fig. 8b. ERRAT-verified protein structure and the result depicted in Fig. 8c.

\section{Functional analysis}

For functional analysis, the query sequence taken was the amino acid sequence of M4 metalloprotease from B. cereus (PDB ID: 1NPC). Here, transmembrane helix prediction analyzed by TMHMM server 2.0 showed that no transmembrane helix presents in the protein. 5 disorder regions were identified by GlobPlot and the regions were from amino acid number 1-29, 93-135, 186-235, 251-257, and 309-317. In Fig. 9, the bluecolored sections were disordered regions and greencolored regions were globular or ordered domains. Protease digestion is a useful process that is used to know proper metabolism, enzymatic digestion and simplification of high order protein structure. According to results from peptide cutter, there were several cleavage sites for 21 different digestive enzymes for the amino acid sequence of M4 metalloprotease from B. cereus. Table 4 summarized the results obtained by the peptide cutter tool which indicated that total numbers of cleavages were found to be 633 . 


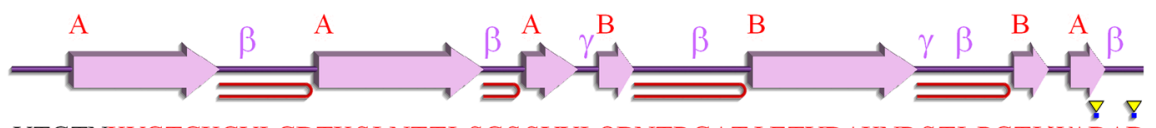

VTGTNKVGTGKGVLGDTKS LNTTL SGS SYYLQDNTRGAT I FTYDAKNRS TLPGTLWADAD
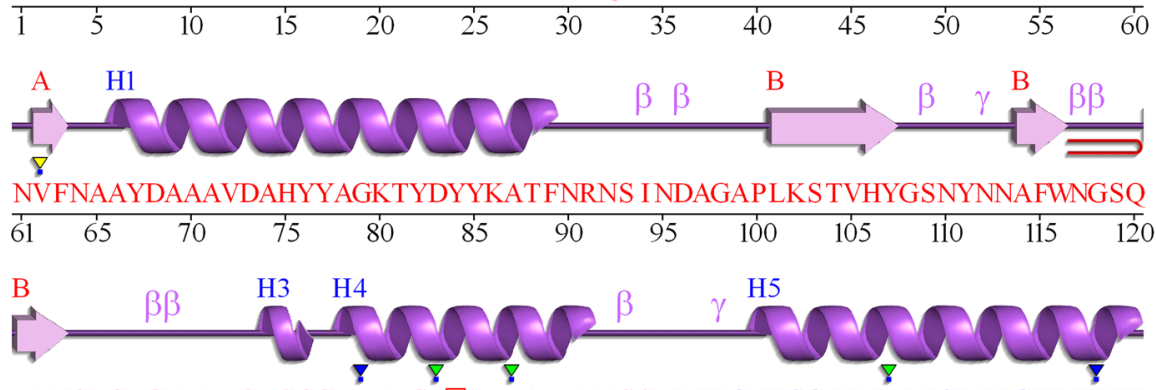

MVYGDGDGVTFT SLSGG I DV I GHEL THAVTENS SNL I YQNE SGALNEA I SD I FGTLVEFY

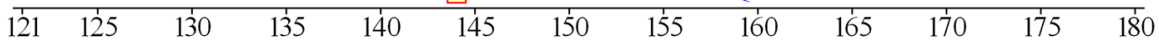

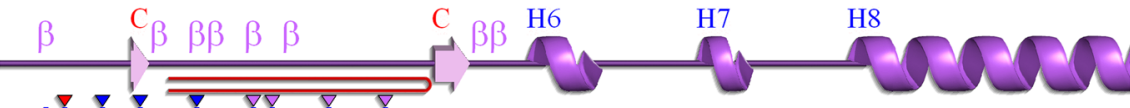

DNRNPDWE I GED I YTPGKAGDALRSMSDPTKYGDPDHY SKRYTGS SDNGGVHTNSG I INK

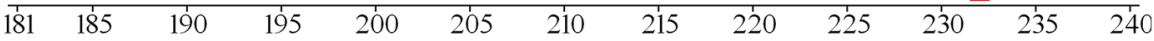

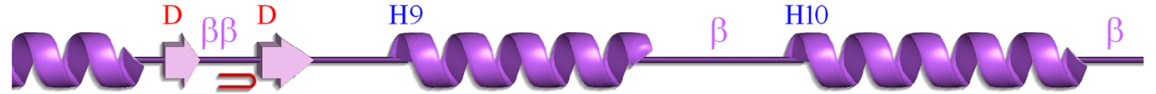

QAYLLANGGTHYGVTVTGIGKDKLGA IYYRANTQYFTQSTTFSQARAGAVQAAADLYGAN

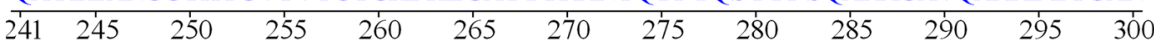

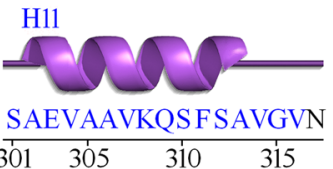

(A)

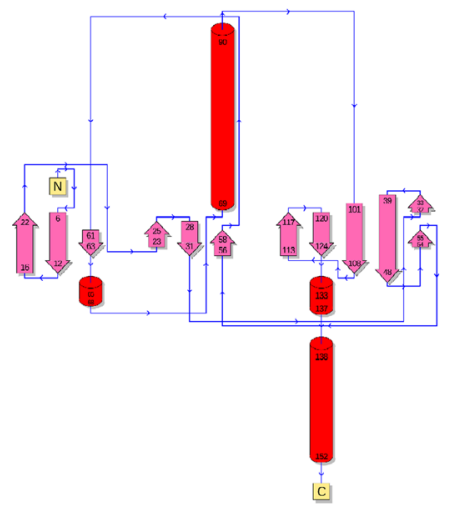

Domain 1

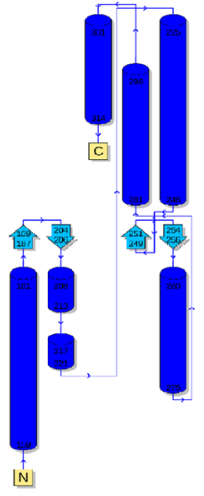

Domain 2

(B)

Fig. 5 Schematic and topology diagrams showing the secondary structural elements in the M4 metalloprotease protein (PDB ID 1NPC), was calculated using the PDBsum tool. a a-Helices were labeled with the letter " $\mathrm{H}$ ", and $\beta$-strands were lettered in uppercase. $\beta, \gamma$, and hairpin turns were also labeled. $\mathbf{b}$ Helices were represented as cylinders and $\beta$-strands as arrows 


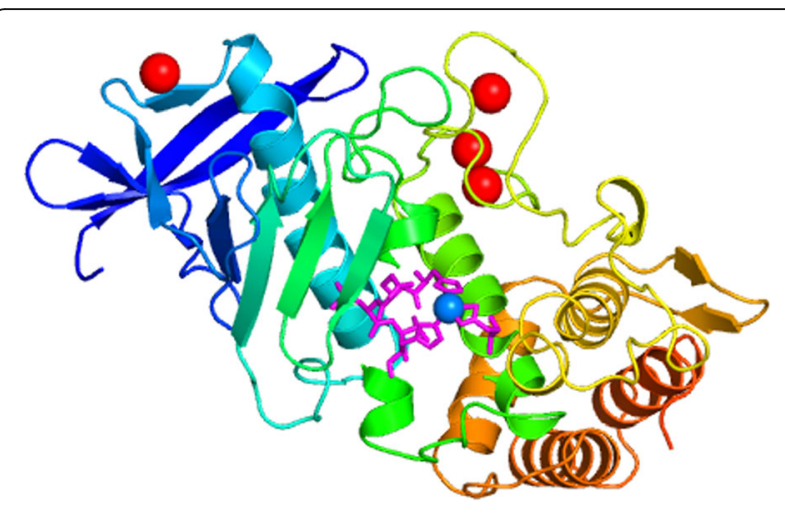

Fig. 6 Predicted 3D structure of B. cereus M4 metalloprotease protein. The model was generated with SWISS-MODEL using PDB template 1NPC. PyMOL was used to visualize the model. The active side lid was shown as a pink loop, $\mathrm{Ca}^{2+}$ binding and $\mathrm{Zn}^{2+}$ binding site was illustrated as red and blue dots, respectively

The protein-protein interacting partners of bacillolysin from $B$. cereus was generated through STRING 11.0 and presented in Fig. 10. STRING forecasted confidence scores (0.771-0.591) which indicated the functional network among the set of proteins of a given organism. M4 metalloprotease of $B$. cereus (npr) was predicted to be interacting with 10 proteins, namely ina, ina_2, plc, DJ87_2940, rseP, DJ87_4517, yloB_1, pruA, rssA_1, and fsr in different manner. The STRING database analysis depicted that npr protein-protein interaction (PPI) network comprised of 11 nodes connected with 20 different edges. Whereas, expected number of edges was observed to be 11; while the average node degree score was found to be 3.64 i.e., one node had at least 3.64 interacting nodes. Average local clustering coefficient was predicted to be 0.732 and PPI enrichment $p$-value was observed as 0.00703 .

\section{Prediction of active sites}

CASTp 3.0 server was used to identify the possible active site for ligand in the M4 metalloprotease of Bacillus cereus (PDB $1 \mathrm{NPC})$. In the present study, the surpass active site area of the enzyme in addition to the number of amino acids occupied in it were also reported. The preeminent active site was found the largest pocket with 103.076 areas and a volume of 76.471 amino acids (Fig. 11). Many functionally important residues were located in this pocket, including three residues His 143, His 147, and Glu 167 in zinc-binding site and two residues, Glu 144 and His 232, in the catalytic site which were essential for the most common HEXXH zinc-binding motif in metalloprotese. Another pocket with an area of 49.147 and a volume of 32.345 amino acids comprising three residues, Glu 167, Asp 171, and Glu 191, in Calcium 2 binding site; four residues, Glu 178, Asn 184, Asp 186, and Glu 191, in Calcium 3 binding site; and four residues, Tyr 194, Thr 195, Lys 198, and Asp 201 in Calcium 4 binding site, since they have also been reported to be essential for the functioning of other bacterial organisms $[2,54,55]$. The 3D representation of pockets was shown in Fig. 11 with largest pocket in red color and other pocket in blue color.

\section{Discussion}

The aim of the study was to identify the structure and properties of M4 metalloprotease proteins using bioinformatics tools. The present study primarily determined the global similarities among the compared proteins. In amino acid sequence alignment of 31 M4 metalloproteases, a conserved region (HELTE) was observed (Fig. 1). The presence of two His and one Glu is important for activity in all the metallopeptidases that carry the HEXXH zinc-binding motif. In case of metallopeptidases having two catalytic metal ions, $\mathrm{Ca}^{2+}$ and $\mathrm{Zn}^{2+}$, along with two residues, a glutamate and an aspartate are also essential [56]. The existence of conserved amino acid plays significant role in confirmation of protein and helix coil transition. Gly and Pro frequently coincide with the extremities of well-structured beta strands or alpha helices. His and Ser are often involved in catalytic sites, especially in proteases. Charged amino acids like Asp, Glu, and Arg are mostly involved in ligand binding. Highly conserved columns might indicate a salt bridge inside the core of the protein [57].

In this study, phylogenetic trees were constructed using both amino acid sequence versus gene sequences to find if there was any correlation among the taxa in terms of their protein sequences compared with respective cDNA. Results obtained from the evolutionary tree (Fig. 2) implied that metalloproteases from different bacterial species appeared to be related to each other and clustering in distinct groups based on its source organisms and nature of the mechanism of enzymatic activity. Thus, it can be inferred that the bacterial strains might be diverged from a common evolutionary ancestor.

A physicochemical analysis of the protein sequence was determined by the Expasy server's ProtParam tool. It revealed all the proteins have negative GRAVY scores which attested to their solubility in hydrophilic solvents and substantiated by earlier studies [58-60]. Average extinction coefficient 78371.13 referred the quantity of light that may be absorbed by protein in $280 \mathrm{~nm}$. In theory, when the pI value of a protein exceeds 7 , it is characterized as alkaline in nature and the value of below 7 indicates the acidic nature. In this study, the pI values of all the proteins showed broad range of 4.88-10 indicating diverse nature of protein. Metalloproteases from all the selected bacteria except $P$. aeruginosa were found to be stable with instability index less than 40, which justified by the previous studies $[58,59]$. The aliphatic index 


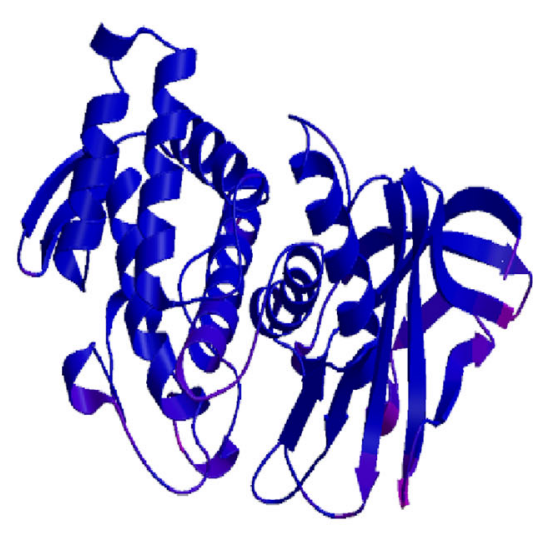

(A)

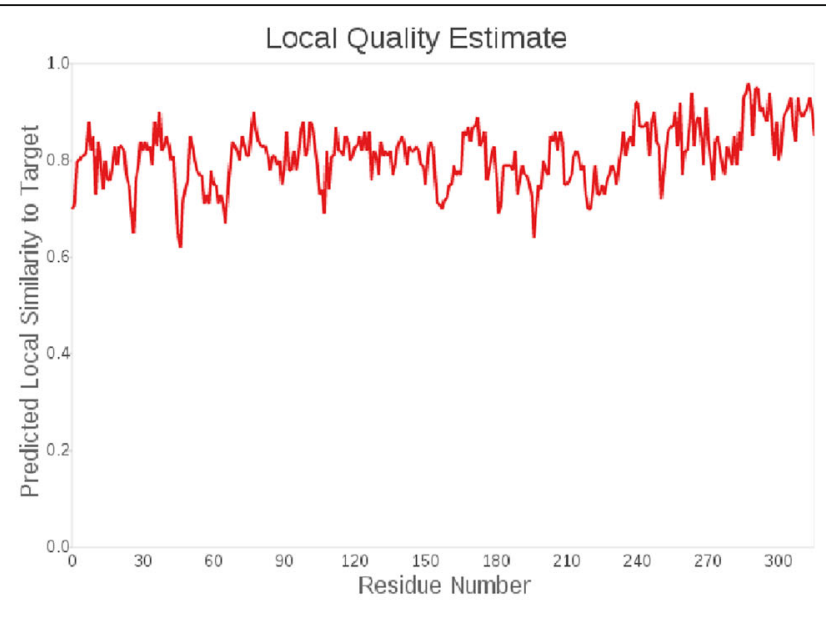

(C)

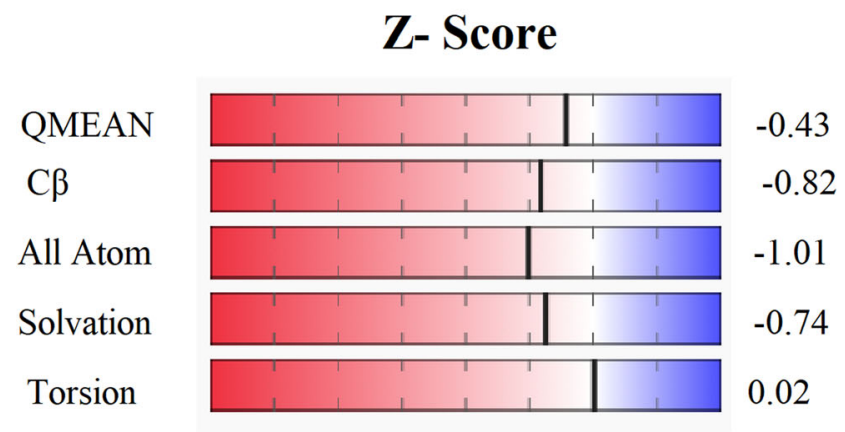

(B)

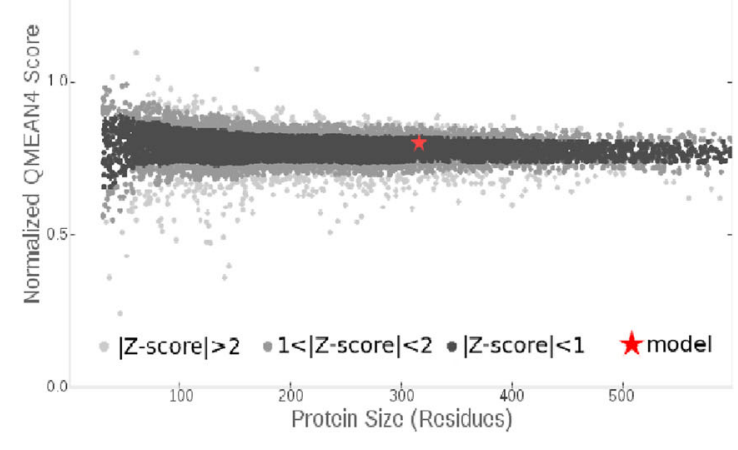

(D)

Fig. 7 Quality analysis of predicted model from QMEAN4 server. a QMEAN PDB 3D model of M4 metalloprotease protein (PDB ID 1NPC) structure. $\mathbf{b}$ The $z$-scores of the QMEAN terms of the protein model PDB ID 1NPC. c Graphical presentation of estimation of local quality. $\mathbf{d}$ Graphical presentation of estimation of absolute quality of model (PDB ID 1NPC)

of a protein is used to measure the relative volume of protein occupied by amino acids in aliphatic side chain [61] and higher value of aliphatic index is considered a positive factor of increased thermo stability. Here, all strains showed high aliphatic index $(\mathrm{Ai})$ of $64.83-81.98$ which indicated the thermostability of the proteins [62].

Based on the amino acid distribution, the most abundant amino acid was Ala which accounted for $9.3 \%$ of the enzyme's primary structure (Fig. 3). The least common amino acid was cysteine. Other predominant amino acids were found to be Gly (9.1\%), Ser (7.8\%), Val (7.5\%), Asp (6.6\%), Lys (6.6\%), and Thr (6.5\%). Ala is very rare to be dug inside the protein core due to its hydrophobic nature so that it has less tendency to contact with water. On the other hand, due to not having a side chain, Gly mostly occupied the surface of the protein providing high flexibility to the polypeptide chain. The presence of significant amount of hydrophilic amino acids such as Ser and Thr represented the protein as extracellular in nature. As Asp is charged and polar amino acid, it might be occurred on the surface of proteins and involved in salt bridge. Being positively charged, Lys preferred to be in the side chain of proteins and formed salt bridge [63]. The domain analysis exposed different conserved site 


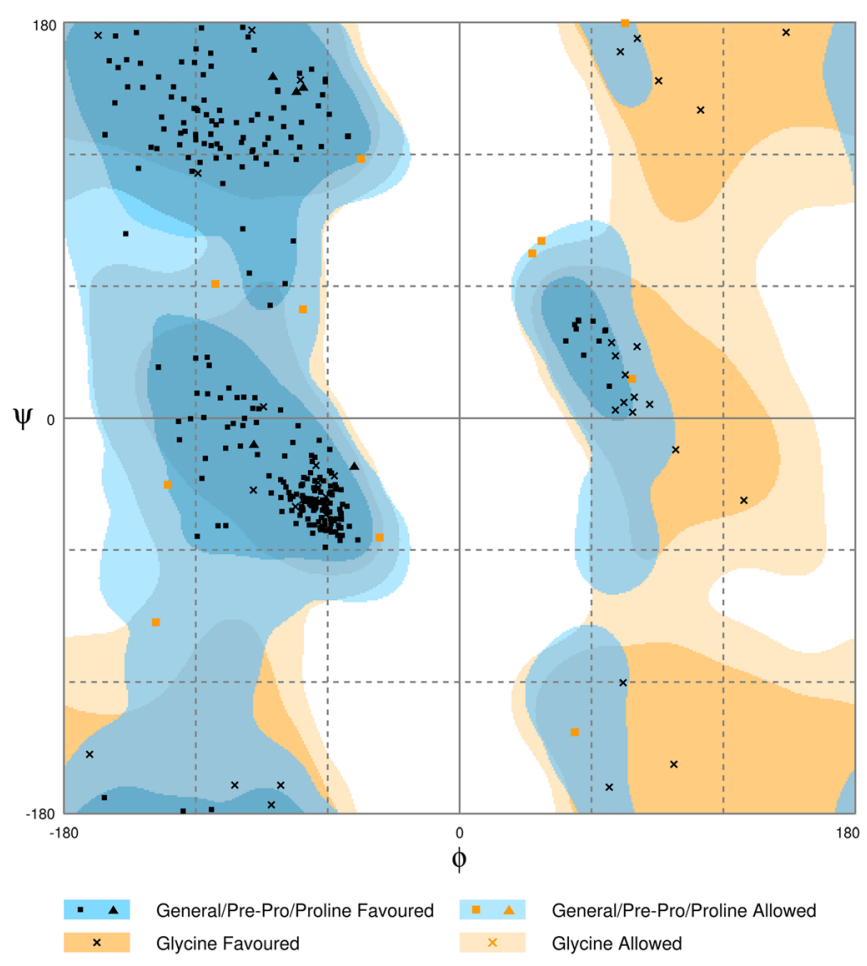

(A)

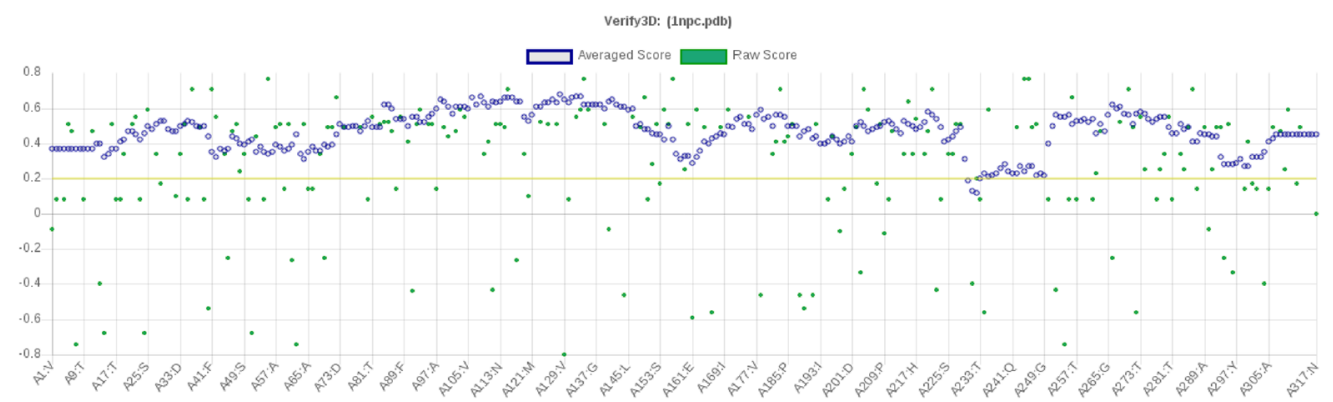

(B)

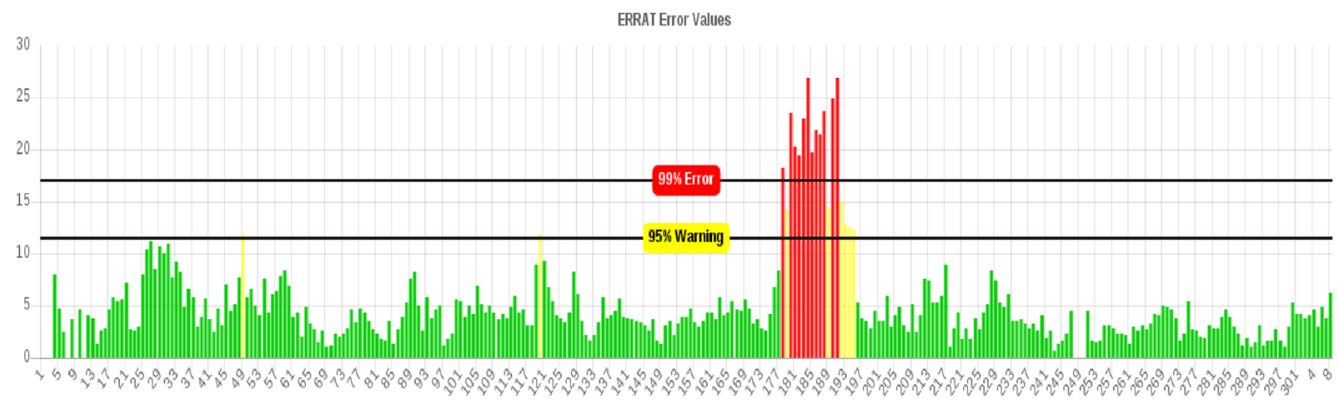

(C)

Fig. 8 Evaluation of bacterial M4 metalloprotease protein (PDB ID 1NPC) form SAVES server. a Ramachandran plot. b Verify 3D graph. c ERRAT generated results 


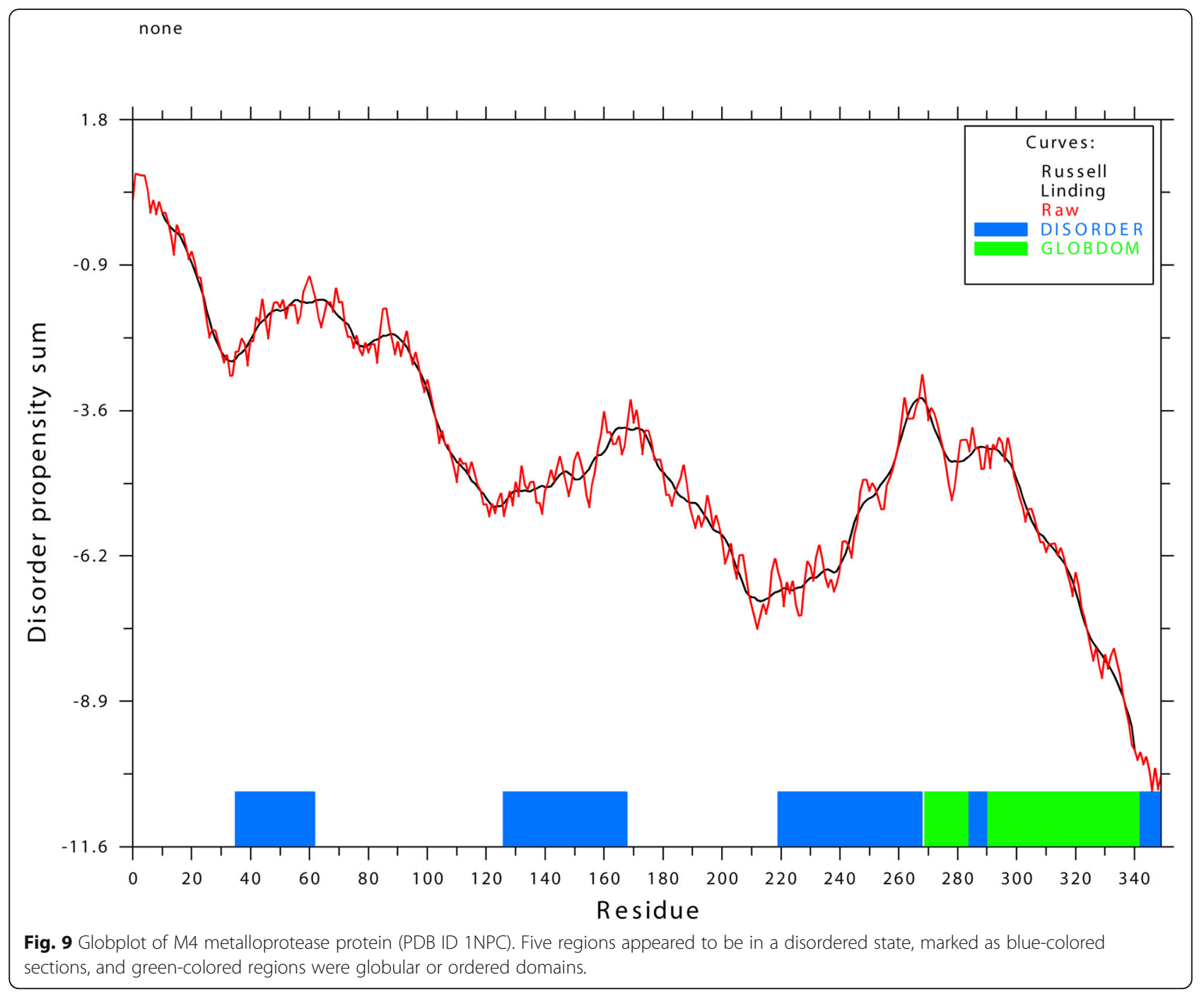

present in M4 metalloprotease from bacterial sources. The presence of common and unique domains among different proteases might confer their structural flexibility, which directly influences functional activity of proteases. These conserved regions might be utilized for designing primers for PCR-based amplification and cloning of these proteases genes from different bacterial species.

In this study, B. cereus M4 metalloprotease (1NPC) was selected as a representative species for describing secondary and tertiary structures of the M4 metalloprotease proteins. Family M4 contains a wide range of extracellular thermolysin. Among them, the 3D structures are known for thermolysin from Bacillus cereus (1NPC) [64] and B. thermoproteolyticus (1KEI) [65]. Thermolysin from $B$. thermoproteolyticus have been well-characterized structurally and enzymatically, i.e., its primary and tertiary structures and substrate-binding site. But very little information is available for thermolysin from Bacillus cereus. This was the reason behind the selection of $B$. cereus M4 metalloprotease (PDB ID: 1NPC). Results generated by secondary structure prediction tool SOPMA showed the abundance of coiled region $(41.64 \%)$ indicated higher conservation and stability of the model 1NPC $[66,67]$. Information from PDBsum aided in determining the overall structural organization of proteins and predicting protein pockets for ligand binding. Thus, the secondary structure arrangement of the protein could help in the prediction of tertiary structures. On the other hand, secondary structural elements prediction may overcome the limitations of X-ray crystallography and NMR for tertiary structure of protein. Crystallization of few proteins is very difficult task by X-ray crystallography and NMR is restricted to relatively small protein molecules. Moreover, Roy et al. [68] reported that prediction of secondary structural elements was vital for detection conformational changes within the protein of interest. 
Table 4 Cleavage of amino acid residues by different enzymes generated by ExPASy peptide cutter

\begin{tabular}{|c|c|c|}
\hline Name of enzyme & $\begin{array}{l}\text { No of } \\
\text { cleavages }\end{array}$ & Positions of cleavage sites \\
\hline Arg-C proteinase & 8 & $36,48,91,183,204,221,270,286$ \\
\hline Asp-N endopeptidase & 23 & $15,32,43,57,59,67,72,82,95,124,126,138,170,180,185,191,200,207,213,215,226,261,294$ \\
\hline $\begin{array}{l}\text { Asp-N endopeptidase }+\mathrm{N} \text { - } \\
\text { terminal Glu }\end{array}$ & 31 & $\begin{array}{l}15,32,43,57,59,67,72,82,95,124,126,138,143,150,160,166,170,177,180,185,187,190,191,200, \\
207,213,215,226,261,294 \text {, and } 302\end{array}$ \\
\hline BNPS-Skatole & 3 & 56,116, and 187 \\
\hline $\mathrm{CNBr}$ & 2 & 121 and 206 \\
\hline Caspase1 & 1 & 58 \\
\hline $\begin{array}{l}\text { Chymotrypsin-high } \\
\text { specificity }\end{array}$ & 37 & $\begin{array}{l}29,30,41,43,56,63,67,76,77,82,84,85,89,107,111,115,116,123,131,158,173,179,180,187,194, \\
212,218,222,243,252,268,269,275,276,282,297 \text {, and } 311\end{array}$ \\
\hline $\begin{array}{l}\text { Chymotrypsin-low } \\
\text { specificity }\end{array}$ & 62 & $\begin{array}{l}14,20,24,29,30,31,41,43,55,56,63,67,75,76,77,82,84,85,89,101,106,107,111,115,116,121,123, \\
131,134,143,145,147,156,158,165,173,176,179,180,187,194,203,206,212,217,218,222,232,243, \\
244,245,251,252,264,268,269,275,276,282,296,297, \text { and } 311\end{array}$ \\
\hline Clostripain & 8 & $36,48,91,183,204,221,270$, and 286 \\
\hline Formic acid & 23 & $16,33,44,58,60,68,73,83,96,125,127,139,171,181,186,192,201,208,214,216,227,262$, and 295 \\
\hline Glutamyl endopeptidase & 8 & $144,151,161,167,178,188,191$, and 303 \\
\hline Hydroxylamine & 3 & 117,228, and 247 \\
\hline lodosobenzoic acid & 3 & 56,116 , and 187 \\
\hline LysC & 14 & $6,11,18,46,80,86,102,198,211,220,240,261,263$, and 308 \\
\hline LysN & 14 & $5,10,17,45,79,85,101,197,210,219,239,260,262$, and 307 \\
\hline Pepsin (pH 1.3) & 45 & $\begin{array}{l}14,19,23,24,30,31,40,41,51,54,55,62,63,89,100,114,115,130,131,133,134,144,155,156,164,165, \\
172,173,175,176,178,179,202,203,243,244,245,264,275,276,281,282,295,296, \text { and } 311\end{array}$ \\
\hline Pepsin $(\mathrm{pH}>2)$ & 81 & $\begin{array}{l}14,19,23,24,28,29,30,31,40,41,42,43,51,54,55,56,62,63,66,67,75,76,81,83,84,85,89,100,106, \\
107,110,111,114,115,116,122,123,130,131,133,134,144,155,156,157,158,164,165,172,173,175, \\
176,178,179,180,187,193,202,203,211,212,217,218,243,244,245,251,252,264,267,268,269,274 \\
275,276,281,282,295,296,297 \text {, and } 311\end{array}$ \\
\hline Proteinase $\mathrm{K}$ & 159 & $\begin{array}{l}1,2,4,7,9,13,14,17,20,22,23,24,29,30,31,35,38,39,40,41,42,43,45,50,51,54,55,56,57,59,62, \\
63,65,66,67,69,70,71,72,74,76,77,78,81,82,84,85,87,88,89,94,97,99,101,104,105,107,111,114, \\
115,116,122,123,129,130,131,132,134,138,140,141,144,145,146,148,149,150,151,156,157,158, \\
161,164,165,167,168,169,172,173,175,176,177,178,179,180,187,188,189,191,193,194,195,199, \\
202,203,210,212,218,222,223,231,233,237,238,242,243,244,245,246,250,252,254,255,256,257, \\
259,264,266,267,268,269,271,273,275,276,277,280,281,282,285,287,289,290,292,293,294,296, \\
297,299,302,303,304,305,306,307,311,313,314 \text {, and 316 }\end{array}$ \\
\hline Staphylococcal peptidase I & 8 & $144,151,161,167,178,188,191$, and 303 \\
\hline Thermolysin & 78 & $\begin{array}{l}6,12,13,19,23,30,37,39,40,54,56,61,62,64,65,69,70,71,77,86,88,93,100,104,113,114,120,121, \\
128,130,133,137,140,147,148,155,156,163,164,168,172,175,176,198,202,205,230,236,237,241 \\
243,244,245,253,255,258,263,265,266,270,275,281,284,286,288,289,291,292,293,298,301,304 \\
305,306,310,312,313 \text {, and } 315\end{array}$ \\
\hline Trypsin & 22 & $6,11,18,36,46,48,80,86,91,102,183,198,204,211,220,221,240,261,263,270,286$, and 308 \\
\hline
\end{tabular}

The protein 3D model gained from SWISS-MODEL workspace was evaluated by both QMEAN4 and SAVES server. QMEAN output estimated geometrical aspects of the protein structure that characterized the global arrangement of variable residues of protease. According to Benkert et al., the QMEAN $z$-score determines of the absolute quality of a model by relating it to the reference structures solved by X-ray crystallography [69]. In Fig. $7 \mathrm{c}$, the $z$-scores of the QMEAN terms of the protein model were $-0.82,-1.01,-0.74$, and 0.02 for $C \beta$ interaction energy, all atom energy, salvation energy, and torsion angle energy, respectively. These scores implied that the predicted protein model could be considered a quality model. Furthermore, for the estimation of perfect quality of the model, the QMEAN server relates the query model with a representative set of high-resolution $\mathrm{X}$-ray structures of similar size and the resulting QMEA $\mathrm{N} z$-score is an extent of degree of nativeness of the particular structure [70]. For high-resolution models, the average $z$-score is ' 0 '. Here, QMEAN $z$-score for the query model was -0.43 , which was lower than the standard deviation ' 1 ' from the mean value ' 0 ' of good models, so this result indicated that the estimated model was comparable to the high-resolution models. Again, from the estimation of absolute quality of modeled protein in Fig. $7 d$, the dark zone indicated that the model 


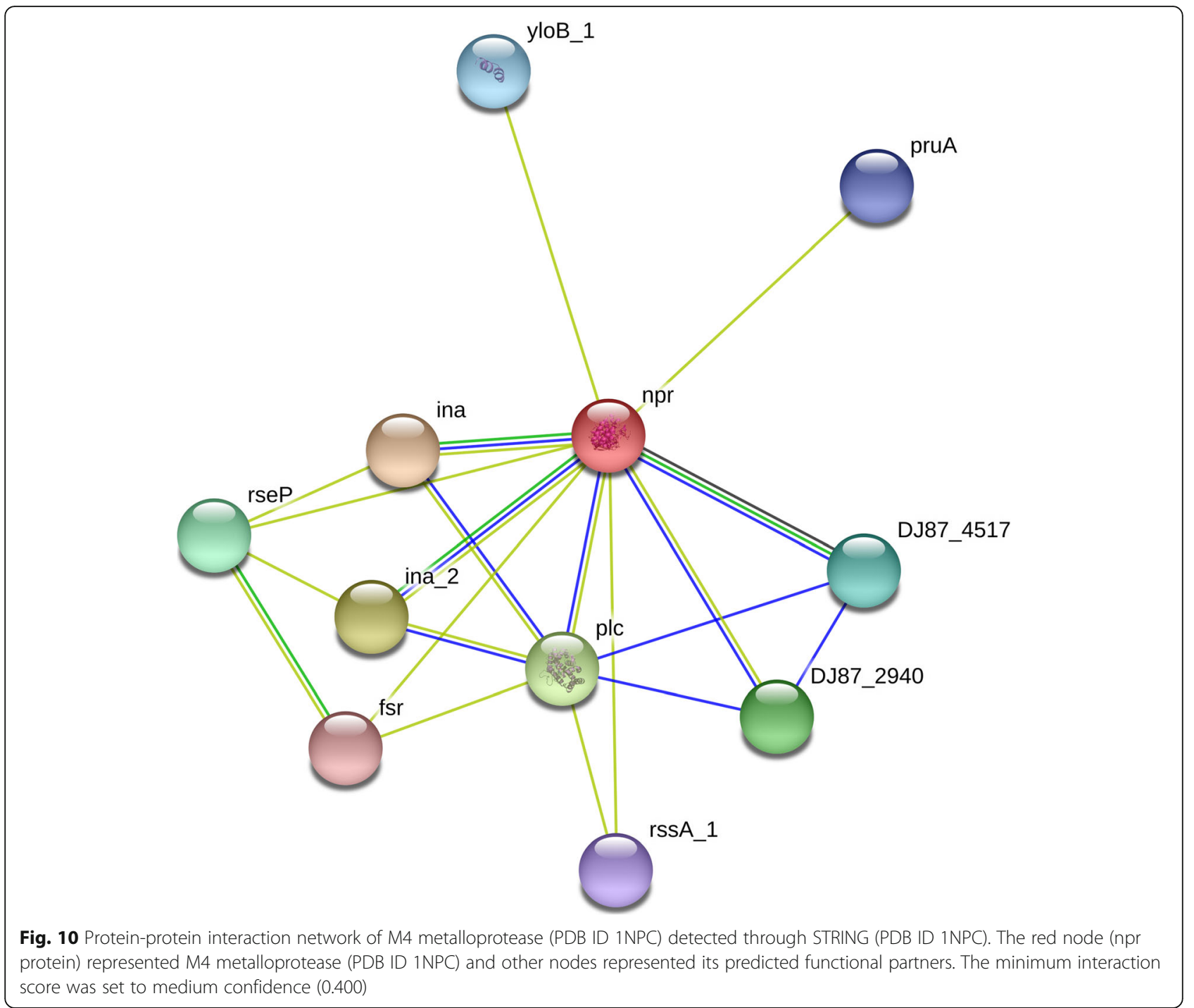

had a score $<1$. Normally, models considered good are expected to position in the dark zone. In this case, the model was considered to be good according to their position in the dark zone which was showed as red marker. This finding was similar with Hasan et al. [71]. The structure of $B$. cereus M4 metalloprotease was further verified using SAVES server. Ramachandran plot, verify 3D, and ERRAT were evaluated from SAVES. These methods were essential for understanding 3D protein models and the estimation of their accuracy. According to the Ramachandran plot generated with the RAMPAGE server, $96.5 \%$ of residues are found in the favored region, while $3.5 \%$ of amino acids reside in the allowed region (Fig. 8). According to Yadav et al., $>90 \%$ of the residues residing in favored region implied the characteristics of a good quality model [72]. Thus, a good stereo-chemical quality of the model was ensured by the
Ramachandran plot, whereas the 3D model passed the Verify 3D with $99.05 \%$ as $99.05 \%$ of its residues had an average 3D-1D score $\geq 0.2$. According to Verify 3D server, at least $80 \%$ of the amino acids has scored $\geq 0.2$ in the 3D/1D profile would be acceptable. Again in ERRA $\mathrm{T}$, the structure verification algorithm interpreted the overall quality of the model with the resulting score 93.33; this score denoted the percentage of the protein that fell below the rejection limit of $95 \%$ [73]. So ERRAT program also verified the protein 3D structure as acceptable. From the above analyses, it was confirmed that predicted structure of the protein was good, stable, reliable, and consistent.

TMHMM tool indicates there was no transmembrane domain present in the protein, confirming the extracellular production nature of $B$. cereus M4 metalloprotease. Similar type of observation regarding the TMHMM 


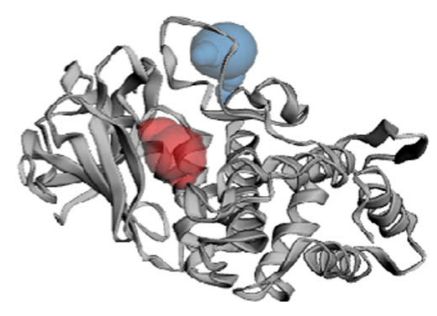

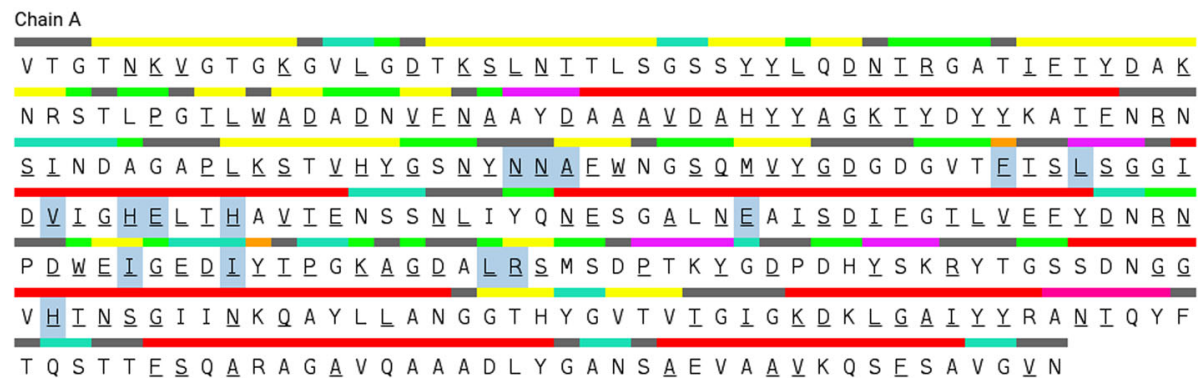

Fig. 11 Active site information of M4 metalloprotease (PDB ID 1NPC) obtained from CASTp serve. a Visualization of pocket automatically identified on the structure of the active site of the protein. $\mathbf{b}$ Active site information. Green color illustrated the amino acids position in active site

result was also shown by Dutta et al. [63]. GlobPlot tool was used to identify disorder regions. Disorder of protein is denoted as a high degree of flexibility in polypeptide chain and lack of regular secondary structure [74]. In Fig. 9, the blue-colored sections were disordered regions. Many proteins are intrinsically found disordered in vivo. Disordered regions are important because many intrinsically disordered proteins exist as unstructured and become structured when bound to another molecule $[75,76]$. According to the result from peptide cutter tool, a total of 633 cleavages were obtained which might be helpful to carry out experiments with a portion of a protein, to separate the domains in a protein, and to remove a tag protein when expressing a fusion protein.

Protein-protein interaction (PPI) networks are used to identify the complex molecular mechanisms and pathways to gain basic knowledge of diseases. PPI network demonstrated that bacillolysin interacted with ten other proteins in a high confidence score, among them the closest annotated interacting protein having the shortest node with score of 0.77 was found ina. Then, ina_2, immune inhibitor A, was found having the score of 0.768 that functioned in degrading host tissue proteins with broad substrate specificity [77]. Again, plc (score 0.662), which stood for Phospholipase $C$, was involved in hemolysis and cell rupture [24]. DJ87_2940 (score 0.647) was an enterotoxin; a nonhemolytic protein, yolB_1 (score 0.595), was a calciumtranslocating P-type ATPase which functioned to transport a variety of different compounds, including ions and phospholipids across a membrane. PruA (score 0.591) was a putative delta-1-pyrroline-5- carboxylate dehydrogenase which was involved in antibiotic biosynthesis pathway. From PPI network analysis, it can be estimated that bacillolysin from $B$. cereus may be a part of its immune system.

Analysis of protein structures for active site often considers as the starting point in the protein-ligand docking studies. The active site of an enzyme comprises a substrate-binding site and a catalytic site. The enzyme binds with a specific substrate in order to catalyze a chemical reaction, whereas the catalytic site occurs next to the binding site, carrying out the catalysis. Some enzymes require the help of cofactors for their activities. Mostly cofactors are connected to the active site of an enzyme. The calculated result from CASTp showed that the amino acid position 112-235 was predicted to be the active site. Metalloproteases from M4 family need $\mathrm{Ca}^{2+}$ and $\mathrm{Zn}^{2+}$ as cofactors which bind with specific amino acid residues in enzyme active site for catalysis. In this study, the zincbinding residues of His-143, His-147, and Glu-167, with Glu-144 having acted as the catalytic residue. Glu144 was responsible for the polarization of the catalytic water molecule leading to an enhancement of nucleophilicity, whereas Asp226 orientated the imidazolium ring of His231 and His231 acted as proton donor and general base [78]. His143 formed a hydrogen bond with Asp171 and had been shown to be essential for activity [79] Tyr158 played a primary role in transition state stabilization and substrate binding [80]. Due to the importance of this active site, it has been widely studied as a target site for antibacterial agents. The 3-D structure of the enzyme is analyzed to identify active site residues as a target site to design drugs which can fit into enzyme. 


\section{Conclusion}

Metalloproteases of M4 family are widely dispersed across the nature. The importance of these proteases has been perceived since their roles in bacterial pathogenicity along with in industrial sectors. The present in silico study reveals the bacterial M4 metalloprotease are thermostable, hydrophillic, and extracellular in nature with diverse molecular mass ranging from 38 to $66 \mathrm{KDa}$. Cross-validation for the 3D model quality assessment was performed by different servers. Hence, this overview may help to get a theoretical idea in developing crossprotective next-generation anti-bacillolysin vaccines as well as to design enzymes with desirable characteristics for biotechnological applications. However, further in vivo studies might be suggested.

\section{Supplementary Information}

The online version contains supplementary material available at https://doi. org/10.1186/s43141-020-00105-y.

Additional file 1: Supplementary Table. Details of 31 different M4 metalloprotease from different bacterial sources used in the study.

Additional file 2: Figure S1. Multiple sequence alignment of M4 metalloprotease amino acid sequences.

\section{Abbreviations \\ Al: Aliphatic index; Ala: Alanine; Arg: Arginine; Asn: Asparagine; Asp: Aspartic acid; BLAST: Basic local alignment search tool; CASTp: Computed atlas of surface topography of proteins; EC: Extinction coefficient; Glu: Glutamic acid; Gly: Glycine; GRAVY: Grand average hydropathicity; His: Histidine; Leu: Leucine; Lys: Lysine; MEGA: Molecular evolutionary genetics analysis; NCBI: National center for biotechnology information; NPS@: Network protein sequence analysis; PDB: Protein data bank; pl: Isoelectric point; PPI: Protein-protein interaction; Pro: Proline; QMEAN: Qualitative model energy analysis; Ser: Serine; SOPMA: Self-optimized prediction method with alignment; STRING: Search tool for the retrieval of interacting genes/proteins; Thr: Threonine; Tyr: Tyrosine; Val: Valine; UniProt: Universal protein}

\section{Acknowledgements}

Authors are thankful to Basic and Applied Research on Jute Project, Bangladesh Jute Research Institute, for pursuing research activities.

\section{Authors' contributions}

$\mathrm{RH}$ and $\mathrm{RA}$ designed the study. $\mathrm{RH}, \mathrm{MNHR}$, and RA performed the experiments and analyzed the data. $\mathrm{RH}$ wrote the manuscript. RA edited and finalized the manuscript and supervised the overall study. All the authors read and approved the manuscript.

\section{Funding}

Not applicable

\section{Availability of data and materials}

All the protein sequences are available in Uniprot. Uniprot ID was provided into the manuscript.

\section{Ethics approval and consent to participate}

Not applicable

\section{Consent for publication}

Not applicable

\section{Competing interests}

The authors declare that they have no conflict of interest in the publication.
Received: 22 March 2020 Accepted: 15 December 2020

Published online: 02 February 2021

\section{References}

1. Barrett AJ (2001) Proteolytic enzymes: nomenclature and classification. In: Beynon RJ, Bond JS (eds) Proteolytic enzymes: a practical approach, 2nd edn. Oxford University Press, Oxford

2. Rawlings ND, Barrett AJ (2013) Introduction: metallopeptidases and their clans. In: Rawlings ND, Salvesen G (eds) Handbook of proteolytic enzymes, 3rd edn. Academic Press, New York

3. Nagase H (2001) Metalloproteases. Current protocols in protein science. Wiley, New York. https://doi.org/10.1002/0471140864.ps2104s24

4. Charles JM (2006) Matrix metalloproteinases (MMPs) in health and disease: an overview. Front Biosci 11:1696. https://doi.org/10.2741/1915

5. Isowa Y, Ohmori M, Ichikawa T et al (1979) The thermolysin-catalyzed condensation reactions of $\mathrm{n}$-substituted aspartic and glutamic acids with phenylalanine alkyl esters. Tetrahedron Lett 20:2611-2612. https://doi.org/ 10.1016/s0040-4039(01)86363-2

6. Ooshima H, Mori H, Harano Y (1985) Synthesis of aspartame precursor by solid thermolysin in organic solvent. Biotechnol Lett 7:789-792. https://doi. org/10.1007/bf01025555

7. Ager DJ, Pantaleone DP, Henderson SA et al (2010) ChemInform abstract: commercial, synthetic nonnutritive sweeteners. Chemlnform. https://doi.org/ 10.1002/chin.199845301

8. Haki G (2003) Developments in industrially important thermostable enzymes: a review. Bioresour Technol 89:17-34. https://doi.org/10.1016/ s0960-8524(03)00033-6

9. Bruins ME, Janssen AEM, Boom RM (2001) Thermozymes and their applications: a review of recent literature and patents. Appl Biochem Biotechnol 90:155-186. https://doi.org/10.1385/abab:90:2:155

10. Durham DR, Fortney DZ, Nanney LB (1993) Preliminary evaluation of vibriolysin, a novel proteolytic enzyme composition suitable for the debridement of burn wound eschar. J Burn Care Rehabil 14:544-551. https://doi.org/10.1097/00004630-199309000-00009

11. Durham DR (1990) The unique stability of Vibrio proteolyticus neutral protease under alkaline conditions affords a selective step for purification and use in amino acid-coupling reactions. Appl Environ Microbiol 56:22772281. https://doi.org/10.1128/aem.56.8.2277-2281.1990

12. Kunugi S, Koyasu A, Kitayaki M et al (1996) Kinetic characterization of the neutral protease vimelysin from Vibrio sp. T1800. Eur J Biochem 241:368373. https://doi.org/10.1111/j.1432-1033.1996.00368.x

13. Wang Y, Liu B-X, Cheng J-H et al (2020) Characterization of a new M4 metalloprotease with collagen-swelling ability from marine Vibrio pomeroyi strain 12613. Front Microbiol. https://doi.org/10.3389/fmicb.2020.01868

14. Clapés P, Torres J-L, Adlercreutz P (1995) Enzymatic peptide synthesis in low water content systems: preparative enzymatic synthesis of [Leu]- and [Met]enkephalin derivatives. Bioorg Med Chem 3:245-255. https://doi.org/10. 1016/0968-0896(95)00019-d

15. Clapés P, Pera E, Torres J (1997) Peptide bond formation by the industrial protease, neutrase, in organic media. Biotechnol Lett 19:1023-1026. https:// doi.org/10.1023/a:1018407619672

16. Rival S, Saulnier J, Wallach J (2000) On the mechanism of action of pseudolysin: kinetic study of the enzymatic condensation of Z-Ala with Phe$\mathrm{NH2}$. Biocatalysis Biotransformation 17:417-429. https://doi.org/10.3109/ 10242420009003633

17. Lunde C, Gjermansen M (2019) Use of M4 metalloprotease in wort production. US Patent No US 10,450, 539 B2, 22 Oct 2019.

18. Eichhorn U, Bommarius AS, Drauz K, Jakubke H-D (1997) Synthesis of dipeptides by suspension-to-suspension conversion via thermolysin catalysis: from analytical to preparative scale. J Pept Sci 3:245-251. https:// doi.org/10.1002/(sici)1099-1387(199707)3:4<245:..aid-psc98>3.0.co;2-|

19. Krix G, Eichhorn U, Jakubke H-D, Kula M-R (1997) Protease-catalyzed synthesis of new hydrophobic dipeptides containing non-proteinogenic amino acids. Enzyme Microbial Technol 21:252-257. https://doi.org/10.1016/ s0141-0229(97)00037-9

20. Adekoya OA, Sylte I (2009) The thermolysin family (M4) of enzymes: therapeutic and biotechnological potential. Chem Biol Drug Design 73:7-16. https://doi.org/10.1111/j.1747-0285.2008.00757.x

21. Goguen JD, Hoe NP, Subrahmanyam YV (1995) Proteases and bacterial virulence: a view from the trenches. Infect Agents Dis 4:47-54 PMID: 7728356 
22. Jin F, Matsushita O, Katayama S et al (1996) Purification, characterization, and primary structure of Clostridium perfringens lambda-toxin, a thermolysinlike metalloprotease. Infect Immun 64:230-237. https://doi.org/10.1128/iai. 64.1.230-237.1996

23. Smith AW, Chahal B, French GL (1994) The human gastric pathogen Helicobacter pylori has a gene encoding an enzyme first classified as a mucinase in Vibrio cholerae. Mol Microbiol 13:153-160. https://doi.org/10. 1111/j.1365-2958.1994.tb00410.x

24. Nanney LB, Fortney DZ, Durham DR (1995) Effect of vibriolysin, an enzymatic debriding agent, on healing of partial-thickness burn wounds. Wound Repair Regen 3:442-448. https://doi.org/10.1046/j.1524-475x.1995. 30408.x

25. Booth BA, Boesman-Finkelstein M, Finkelstein RA (1983) Vibrio cholerae soluble hemagglutinin/protease is a metalloenzyme. Infect Immun 42:639644. https://doi.org/10.1128/iai.42.2.639-644.1983

26. Sahney NN, Miller RD, Ramirez JA, Summersgill JT (2001) Inhibition of oxidative burst and chemotaxis in human phagocytes by Legionella pneumophila zinc metalloprotease. J Med Microbiol 50:517-525. https://doi. org/10.1099/0022-1317-50-6-517

27. Conlan JW, Williams A, Ashworth LAE (1988) Inactivation of human -1antitrypsin by a tissue-destructive protease of Legionella pneumophila. Microbiology 134:481-487. https://doi.org/10.1099/00221287-134-2-481

28. Mintz CS, Miller RD, Gutgsell NS, Malek T (1993) Legionella pneumophila protease inactivates interleukin-2 and cleaves CD4 on human T cells. Infect Immun 61:3416-3421. https://doi.org/10.1128/iai.61.8.3416-3421.1993

29. Schmidtchen A, Holst E, Tapper H, Björck L (2003) Elastase-producing Pseudomonas aeruginosa degrade plasma proteins and extracellular products of human skin and fibroblasts, and inhibit fibroblast growth. Microbial Pathog 34:47-55. https://doi.org/10.1016/s0882-4010(02)00197-3

30. Ma L, Zhou L, Lin J et al (2019) Manipulation of the silkworm immune system by a metalloprotease from the pathogenic bacterium Pseudomonas aeruginosa. Dev Comp Immunol 90:176-185. https://doi.org/10.1016/j.dci. 2018.09.017

31. Clare BW, Scozzafava A, Supuran CT (2001) Protease inhibitors: synthesis of a series of bacterial collagenase inhibitors of the sulfonyl amino acyl hydroxamate type. J Med Chem 44:2253-2258. https://doi.org/10.1021/ jm010087e

32. Travis J, Potempa J (2000) Bacterial proteinases as targets for the development of second-generation antibiotics. Biochim Biophys Acta 1477: 35-50. https://doi.org/10.1016/s0167-4838(99)00278-2

33. Sievers F, Wilm A, Dineen D et al (2011) Fast, scalable generation of highquality protein multiple sequence alignments using Clustal Omega. Mol Syst Biol 7:539. https://doi.org/10.1038/msb.2011.75

34. Gasteiger E, Hoogland C, Gattiker A et al (2005) Protein identification and analysis tools on the ExPASy server. In: Walker JM (ed) The proteomics protocols handbook. Humana Press, pp 571-607.

35. Kumar S, Stecher G, Li M et al (2018) MEGA X: Molecular evolutionary genetics analysis across computing platforms. Mol Biol Evol 35:1547-1549. https://doi.org/10.1093/molbev/msy096

36. Saitou N, Nei M (1987) The neighbor-joining method: a new method for reconstructing phylogenetic trees. Mol Biol Evol 4:406-425. https://doi.org/ 10.1093/oxfordjournals.molbev.a040454

37. Zuckerkandl E, Pauling L (1965) Evolutionary divergence and convergence in proteins. In: Bryson V, Vogel HJ (eds) Evolving Genes and Proteins. Academic Press, New York, pp 97-166

38. Tamura K, Nei M, Kumar S (2004) Prospects for inferring very large phylogenies by using the neighbor-joining method. Proc Natl Acad Sci 101: 11030-11035. https://doi.org/10.1073/pnas.0404206101

39. Bailey TL, Elkan C (1994) Fitting a mixture model by expectation maximization to discover motifs in biopolymers. In: Proceedings of the 2 nd International Conference on Intelligent Systems for Molecular Biology. AAAI Press, pp 28-36.

40. Laskowski RA (2004) PDBsum more: new summaries and analyses of the known 3D structures of proteins and nucleic acids. Nucleic Acids Res. https://doi.org/10.1093/nar/gki001

41. Arnold K, Bordoli L, Kopp J, Schwede T (2005) The SWISS-MODEL workspace: a web-based environment for protein structure homology modelling. Bioinformatics 22:195-201. https://doi.org/10.1093/ bioinformatics/bti770

42. DeLano WL (2002) The PyMOL molecular graphics system. Delano Scientific, San Carlos
43. Lovell SC, Davis IW, Arendall WB et al (2003) Structure validation by Ca geometry: $\varphi, \psi$ and $C \beta$ deviation. Proteins Struct Funct Bioinformatics 50 : 437-450. https://doi.org/10.1002/prot.10286

44. Eisenberg D, Lüthy R, Bowie JU (1997) VERIFY3D: Assessment of protein models with three-dimensional profiles. Methods Enzymol Macromol Crystallogr Part B:396-404. https://doi.org/10.1016/s0076-6879(97)77022-8

45. Macarthur MW, Laskowski RA, Thornton JM (1994) Knowledge-based validation of protein structure coordinates derived by X-ray crystallography and NMR spectroscopy. Curr Opin Struct Biol 4:731-737. https://doi.org/10. 1016/s0959-440x(94)90172-4

46. Bowie J, Luthy R, Eisenberg D (1991) A method to identify protein sequences that fold into a known three-dimensional structure. Science 253: 164-170. https://doi.org/10.1126/science.1853201

47. Krogh A, Larsson B, Heijne GV, Sonnhammer EL (2001) Predicting transmembrane protein topology with a hidden markov model: application to complete genomes 11Edited by F. CohenJ Mole Biol 305:567-580. doi: https://doi.org/10.1006/jmbi.2000.4315.

48. Linding R (2003) GlobPlot: exploring protein sequences for globularity and disorder. Nucleic Acids Res 31:3701-3708. https://doi.org/10.1093/nar/gkg519

49. Szklarczyk D, Gable AL, Lyon D et al (2018) STRING v11: protein-protein association networks with increased coverage, supporting functional discovery in genome-wide experimental datasets. Nucleic Acids Res. https:// doi.org/10.1093/nar/gky1131

50. Tian W, Chen C, Liang J (2018) CASTp 3.0: Computed atlas of surface topography of proteins and beyond. Biophys J. https:/doi.org/10.1016/j.bpj.2017.11.325

51. Tang B, Nirasawa S, Kitaoka M et al (2003) General function of N-terminal propeptide on assisting protein folding and inhibiting catalytic activity based on observations with a chimeric thermolysin-like protease. Biochem Biophys Res Commun 301:1093-1098. https://doi.org/10.1016/s0006-291x(03)00084-6

52. Yeats C, Rawlings ND, Bateman A (2004) The PepSY domain: a regulator of peptidase activity in the microbial environment? Trends Biochem Sci 29: 169-172. https://doi.org/10.1016/j.tibs.2004.02.004

53. Laskowski RA, Jabłońska J, Pravda L et al (2017) PDBsum: Structural summaries of PDB entries. Protein Sci 27:129-134. https://doi.org/10.1002/pro.3289

54. Jackson SG, Zhang F, Chindemi P et al (2009) Evidence of kinetic control of ligand binding and staged product release in MurA (Enolpyruvyl UDPGlcNAc Synthase)-catalyzed reactions. Biochemistry 48:11715-11723. https:// doi.org/10.1021/bi901524q

55. Thomas AM, Ginj C, Jelesarov I et al (2004) Role of K22 and R120 in the covalent binding of the antibiotic fosfomycin and the substrate-induced conformational change in UDP-N-acetylglucosamine enolpyruvyl transferase. Eur J Biochem 271:2682-2690. https://doi.org/10.1111/j.1432-1033.2004.04196.x

56. Rawlings ND, Morton FR, Barrett AJ (2007) An Introduction to peptidases and the Merops Database. In: Polaina J, MacCabe AP (eds) Industrial Enzymes. Springer, Dordrecht, pp 161-179

57. Claverie JM, Notredame C (eds) (2007) Bioinformatics for dummies, 2nd edn. Wiley Publishing, New York

58. Verma A, Singh VK, Gaur S (2016) Computational based functional analysis of Bacillus phytases. Comput Biol Chem 60:53-58. https://doi.org/10.1016/j. compbiolchem.2015.11.001

59. Pramanik K, Soren T, Mitra S, Maiti TK (2017) In silico structural and functional analysis of Mesorhizobium ACC deaminase. Comput Biol Chem 68:12-21. https://doi.org/10.1016/j.compbiolchem.2017.02.005

60. Mushtaq A, Jamil A, Cruz-Reyes J et al (2020) Isolation and characterization of nprB, a novel protease from Streptomyces thermovulgaris. Pak J Pharm Sci 33:2361-2369. https://doi.org/10.36721/ PJPS.2020.33.5.SUP.2361-2369.1

61. Morya VK, Yadav S, Kim E-K, Yadav D (2011) In Silico characterization of alkaline proteases from different species of Aspergillus. Appl Biochem Biotechnol 166:243-257. https://doi.org/10.1007/s12010-011-9420-y

62. Rawlings ND, Morton FR, Barrett AJ (2006) MEROPS: the peptidase database. Nucleic Acids Res 34:D270-D272. https://doi.org/10.1093/nar/gkj089

63. Dutta B, Banerjee A, Chakraborty P, Bandopadhyay R (2018) In silico studies on bacterial xylanase enzyme: Structural and functional insight. J Genet Eng Biotechnol 16:749-756. https://doi.org/10.1016/j.jgeb.2018.05.003

64. Stark W, Pauptit RA, Wilson KS, Jansonius JN (1992) The structure of neutral protease from Bacillus cereus at 0.2-nm resolution. Eur J Biochem 207:781-791. https://doi.org/10.1111/j.1432-1033.1992.tb17109.x

65. Matthews BW, Colman PM, Jansonius JN et al (1972) Structure of thermolysin. Nat New Biol 238:41-43. https://doi.org/10.1038/ newbio238041a0 
66. Hasan A, Mazumder HH, Khan A et al (2014) Molecular characterization of Legionellosis drug target candidate enzyme phosphoglucosamine mutase from Legionella pneumophila (strain Paris): an in silico approach. Genomics Inform 12:268. https://doi.org/10.5808/gi.2014.12.4.268

67. Geourjon C, Deléage G (1995) SOPMA: significant improvements in protein secondary structure prediction by consensus prediction from multiple alignments. Bioinformatics 11:681-684. https://doi.org/10.1093/ bioinformatics/11.6.681

68. Roy S, Banerjee V, Das KP (2015) Understanding the physical and molecular basis of stability of Arabidopsis DNA pol $\lambda$ under UV-B and high $\mathrm{NaCl}$ stress. PLoS One 10(7):e0133843. https://doi.org/10.1371/journal.pone.0133843

69. Benkert P, Künzli M, Schwede T (2009) QMEAN server for protein model quality estimation. Nucleic Acids Res 37:510-514. https:/doi.org/10.1093/ nar/gkp322

70. Benkert $P$, Biasini $M$, Schwede $T$ (2010) Toward the estimation of the absolute quality of individual protein structure models. Bioinformatics 27: 343-350. https://doi.org/10.1093/bioinformatics/btq662

71. Hasan MA, Mazumder MHH, Chowdhury AS et al (2015) Molecular-docking study of malaria drug target enzyme transketolase in Plasmodium falciparum 3D7 portends the novel approach to its treatment. Source Code Biol Med. https://doi.org/10.1186/s13029-015-0037-3

72. Yadav PK, Singh G, Gautam B et al (2013) Molecular modeling, dynamics studies and virtual screening of Fructose 1, 6 biphosphate aldolase-II in community acquired- methicillin resistant Staphylococcus aureus (CA-MRSA). Bioinformation 9:158-164. https://doi.org/10.6026/97320630009158

73. Wright PE, Dyson H (1999) Intrinsically unstructured proteins: re-assessing the protein structure-function paradigm. J Mol Biol 293:321-331. https://doi. org/10.1006/jmbi.1999.3110

74. Hasan MA, Khan MA, Datta A et al (2015) A comprehensive immunoinformatics and target site study revealed the corner-stone toward Chikungunya virus treatment. Mol Immunol 65:189-204. https://doi.org/10. 1016/j.molimm.2014.12.013

75. Uversky VN (2002) Natively unfolded proteins: A point where biology waits for physics. Protein Sci 11:739-756. https://doi.org/10.1110/ps.4210102

76. Dunker A, Lawson J, Brown CJ et al (2001) Intrinsically disordered protein. J Mol Graph Model 19:26-59. https://doi.org/10.1016/s1093-3263(00)00138-8

77. Arolas JL, Goulas T, Pomerantsev AP et al (2016) Structural basis for latency and function of immune inhibitor A metallopeptidase, a modulator of the Bacillus anthracis secretome. Structure 24:25-36. https://doi.org/10.1016/j.str. 2015.10.015

78. Argos P, Garavito R, Eventoff W et al (1978) Similarities in active center geometries of zinc-containing enzymes, proteases and dehydrogenases. J Mol Biol 126:141-158. https://doi.org/10.1016/0022-2836(78)90356-x

79. Pelmenschikov V, Blomberg MR, Siegbahn PE (2002) A theoretical study of the mechanism for peptide hydrolysis by thermolysin. JBIC J Biol Inorg Chem 7:284-298. https://doi.org/10.1007/s007750100295

80. Rawlings ND (2000) MEROPS: the peptidase database. Nucleic Acids Res 28 : 323-325. https://doi.org/10.1093/nar/28.1.323

\section{Publisher's Note}

Springer Nature remains neutral with regard to jurisdictional claims in published maps and institutional affiliations.

\section{Submit your manuscript to a SpringerOpen ${ }^{\circ}$ journal and benefit from:}

- Convenient online submission

- Rigorous peer review

- Open access: articles freely available online

- High visibility within the field

- Retaining the copyright to your article

Submit your next manuscript at $\boldsymbol{\nabla}$ springeropen.com 